\title{
O CINTURÃO METAVULCANOSSEDIMENTAR BRUSQUE E A EVOLUÇÃO POLICÍCLICA DAS FAIXAS DOBRADAS PROTEROZÓICAS NO SUL DO BRASIL: UMA REVISÃO
}

\author{
LUIZ C. SILVA
}

\begin{abstract}
THE BRUSQUE METAVOLCANIC-SEDIMENTARY BELT AND THE POLICYCLIC EVOLUTION OF THE PROTEROZOIC FOLDED BELTS IN SOUTHERN BRAZIL: A REVIEW. Some recent $\mathrm{Sm}-\mathrm{Nd}, \mathrm{Pb}-\mathrm{Pb}$ and $\mathrm{U}-\mathrm{Pb}$ isotopic ages obtained in metasediments and granites related to the Brusque Complex, just confirm a field chronology, based on regional geological surveys which permitted to antecipate, by almost a decade, the policyclical evolution of the Proterozoic terranes in Southern Brazil. A review of the field and petrological constraints wich led to this approach is herein presented. Major aspects emphasized are the characterization of two cycles of crustal extension, ensialic rifting, associated with: 1. shallow and deep water marine sedimentation, submarine mafic-ultramafic volcanism, possible ocean floor generation and consume (Brusque Complex) and; 2. continental and marine (deltaic) deposits, mafic to intermediate- and felsic-alkaline subaerial volcanism; "A" type plutonism (Itajaí-Campo Alegre basins). In the absence of appropriated isotopic refinement $\mathrm{T}$ based on circunstancial evidences - the age of the first rifting phase (Brusque) is inferred to be largely Early to Middle Proterozoic. The second phase (Itajaí-Campo Alegre) has an isotopic record in the Upper Proterozoic to Early Paleozoic interval. As a consequence, the evolution of the Brusque Complex favors "B" - like subduction models following the first Proterozoic crustal fragmentation. Finally, they are discussed the current attempts to establish direct correlations of the Brusque Complex with some Brasiliano belts from the Paraná Block and from abroad, specially with respect to the Pan-African. Western Damara Belt.
\end{abstract}

Keywords: Brusque Complex, mafic schists, variolitic metabasalts, stratabound tourmalinites, exhalites, Damara Belt.

\begin{abstract}
RESUMO Datações isotópicas $\mathrm{Sm}-\mathrm{Nd}, \mathrm{Pb}-\mathrm{Pb}$ e $\mathrm{U}-\mathrm{Pb}$, recentemente obtidas em metassedimentos e em granites relacionados ao Complexo Brusque, confirmam uma cronologia de campo, baseada em levantamentos geológicos em escala regional, que permitiram a antecipação em quase uma década da hoje reconhecida evolução policíclica dos terrenos proterozóicos do sul do país. Uma revisão dos principais argumentos de campo e petrológicos que conduziram a esse posicionamento é apresentada. Os principais aspectos enfatizados foram o reconhecimento de dois ciclos de extensão crustal e rifteamento ensiálico associado a 1. sedimentação marinha e vulcanismo submarino máfico-ultramáfíco, com possível geração e consumo de assoalho oceânico (Complexo Brusque) e 2. sedimentação continental e marinha (deltaica), vulcanismo máfico-intermediário e félsico-alcalino subaéreo, plutonismo granítico do tipo "A" (Bacias Itajaí - Campo Alegre). A época de desenvolvimento da primeira fase (Brusque), na ausência de detalhamento isotópico adequado, foi inferida - por evidências circunstanciais - no intervalo Proterozóico Inferior a Médio. A fase mais recente (Itajaí - Campo Alegre) tem amplo registro isotópico no intervalo Proterozóico Superior-Eopaleozóico. Dessa forma, a evolução do Complexo Brusque parece favorecer mecanismos de subducção similares ao tipo "B", induzida pela primeira fase de fragmentação crustal proterozóica. Finalmente, são reavaliadas as tentativas de estabelecer correlações diretas do Complexo Brusque com alguns cinturões brasilianos do Bloco Paraná e de outras regiões, especialmente com o cinturão pan-africano do Damara ocidental.
\end{abstract}

Palavras-chaves: Complexo Brusque, xistos máficos, metabasaltos variolíticos, turmalinitos estratabound, exalitos, Cinturão Damara.

INTRODUÇÃO A recente divulgação de datações radiométricas ( $\mathrm{Sm}-\mathrm{Nd}$ e $\mathrm{Pb}-\mathrm{Pb}$ ), próximas de $2.000 \mathrm{Ma}$ para os protólitos metassedimentares e granitóides associados ao Grupo Brusque em Santa Catarina (Mantovani et al 1987) confirmam, após quase uma década, resultados obtidos em sucessivos levantamentos geológicos que, já em 1981, sugeriam uma natureza policíclica para os terrenos proterozóicos na região Sul. Esses levantamentos, mesmo na ausência de dados isotópicos, evidenciavam dois períodos principais de acresção continental e sugeriam - pelas peculiaridades faciológicas e por correrlação com cinturões similares -, idade (mínima) de 1.800 Ma (Silva \& Dias 1981, Silva 1983a, b, Silva et al 1985). Essa cronologia relativa de campo constituiu-se por muito tempo no único argumento circunstancial capaz de minimizar a incômoda ucroniá que dificultava as tentativas de posicionamento temporal do Cinturão Brusque, na evolução proterozóiea no sul do País.

O primeiro estágio no estabelecimento de uma abordagem alternativa para a evolução do Pré-Cambriano de Santa Catarina foi proporcionado pelo reconhecimento de um insuspeitado ciclo vulcanossedimentar precoce, no então redenominado Complexo Metamórfico Brusque (Silva \& Dias 1981). A partir destas descobertas, estabeleceram-se parâmetros objetivos de comparação estrutural, faciológica e metamórfico-deformacional, com diversos cinturões vulcanossedimentares, então já considerados pré-brasiliarios. Como conseqüência, as supostas afinidades plataformais da Faixa Tijucas na Região de Dobramentos do Sudeste (Almeida 1967, Hasui et al 1975) passou a ser questionada.

As configurações paleobacinais e litofaciais sugeriam uma pré-história crustal, relativa ao evento brasiliano, e uma evolução ensiálica mediante "intensa fragmentação crustal (...) a partir da qual se formaram riftes, com posterior interveniência de processos sedimentares e vulcanogênicos associados, que viriam a constituir-se no cinturão Brusque" (Silva $\&$ Dias 1981). A verdadeira dimensão geológica desses processos só seria plenamente estabelecida em 1983, com a descoberta de diversas associações vulcânicas, piroclásticas ou tufíticas, incluindo basaltos maciços, amigdaloidais e variolíticos, tufos bandados e brechas de composição máfico-ultramáfica, além de metaexalitos diversos (Silva 1983a, b). Academicamente, a conseqüência mais imediata dessas des- 
cobertas foi o estabelecimento de uma polêmica, até hoje não esgotada, sobre a evolução das Faixas de Dobradas proterozóicas na região sul, possibilitando as atuais especulações sobre o desenvolvimento de assoalho oceânico no cinturão. Institucinalmente, elas levaram - num caso inédito em todo o País - ao remapeamento, na mesma escala (1:50.000), pelo Programa Levantamentos Geológicos Básicos do Brasil (PLGB), das Folhas Brusque e Botuverá (15x15), nas quais essas associações não tinham sido previamente identificadas.

A racionalização litoestratigráfica possibilitou o questionamento dos enfoques correntes que vinculavam as principais entidades supracrustais do Pré-Cambriano catarinense a um único ciclo orogênico, representado pelo suposto sistema orógeno/molassa - cinturão Brusque/Bacia Itajaí - Campo Alegre: "O significado geotectônico do Grupo Itajai e, ao nosso ver, ainda questionável. Sua interpretação como um conjunto 'molassóide', relacionado ao fechamento do Ciclo Orogenético Brasiliano, como vem sendo interpretado desde Almeida (1967) (...) não é consistente com os dados ora apresentados (...) uma vez que essas 'molassas' deveriam constituir um evento tardi a pós-tectônico em relação a um ciclo orogênico (no caso o Brasiliano) que, como vimos, parece não ter atuado regionalmente, a menos quê se queira considerar intrusões graniticas, tafrogênese, bem como reativações em zonas rúpteis (sentido geofísica), como um Ciclo Orogenético" (Silva \& Dias 1981, p. 136).

O emprego de tratamento isotópico mais refinado deu maior consistência e este questionamento. Decorrida quase uma década, baseados especialmente em idades-modelo $\mathrm{Nd}$ obtidas nos xistos e granitóides associados ao Brusque (Mantovani et al 1987), retomam, de forma mais ampla, as conclusões anteriormente destacadas: "tanto na Namíbia quanto no sul do Brasil, consideráveis volumes de crosta jovem parecem ter sidos gerados no Proterozóico Médio, enquanto os extensivos eventos tectono-termais Brasiliano e Pan-Africano foram caracterizados por considerável retrabalhamento crustale insignificante geração de novo material crustal. "

Se confirmados alguns resultados recentemente obtidos pelo método U-Pb em zircões de metarriodacitos, com valores em torno de 2.000 Ma (M.A.S. Basei 1989, informação escrita), estaria caracterizado um lapso temporal de cerca de 1.500 Ma entre o vulcanismo félsico do Cinturão Brusque e o vulcano-plutonismo Itajaí e Campo Alegre - intervalo temporal demasiado dilatado para a evolução de um par orógeno/molassa, qualquer que tenha sido o sentido empregado para tais unidades geotectônicas.

Os dados disponíveis sobre o suposto par orógeno/molassa favorecem uma evolução policíclica, ensiálica, a partir de dois estágios sucessivos de extensão e rifteamento crustal. Até o presente, não foram estabelecidos parâmetros adequados à estimativa do hiato temporal entre os dois ciclos. Contudo, a contribuição dos metamorfitos Brusque no preenchimento da fossa Itajaí implica em razoável intervalo temporal necessário para completar os processos de metamorfismo, exumação, intemperismo e redeposição - incluindo exposição subaérea prolongada sob condições oxidantes -, sob um regime de leques aluviais do tipo red beds (Silva \& Dias 1981). Assim, um hiato de várias centenas de milhões de anos entre o preenchimento das Bacias Brusque e Itajaí pode ser assumido.

Generalidades O Complexo Brusque tern a forma de um estreito cinturão estendendo-se no sentido S45W, desde a cidade de Itajaí, até as proximidades de Vidal Ramos, cerca de $75 \mathrm{~km}$ a sudoeste, onde é coberto pela Bacia do Paraná. A largura máxima raramente alcança a faixa dos $45 \mathrm{~km}$, incluindo dois plútons graníticos intrusivos, com dimensões batolíticas, que segmentam o cinturão em duas faixas estreitas (Fig. 1).

Os três principais níveis de exposição das associações vulcanossedimentares situam-sé nas extremidades sudoeste e nordeste do cinturão e foram informalmente designados $\mathbf{I}$. Seqüência (Meta) Vulcanossedimentar Ribeirão do Cinema; II. Seqüência (Meta) Vulcanossedimentar Ribeirão do Ouro; e III. Seqüência (Meta) Vulcanossedimentar Rio do Oliveira-Itapema, respectivamente (Fig. I). As duas primeiras, quando da sua identificação, foram designadas de Seqüência Rio Itajaí-Mirim (Silva 1983 a), denominação genérica posteriormente substituída por topônimos locais. Desmembrados da última (III), foram identificados, nos terrenos granito-gnaissicos encaixantes, diversos remanescentes "esfarrapados", na forma de inclusões tectonicamente transpostas, rotacionadas e trazidas em concordância com o bandamento milonítico de ortognaisses, em zonas de cisalhamento dúctil de alto (Porto Belo) ou baixo ângulo (Itapema) (Foto B, Prancha 1; Foto A, Esquema B, Prancha 2).

As características microestruturais, petrogenéticas e faciológicas abaixo discutidas foram obtidas quase que exclusivamente nas seqüências (II e III), as quais apresentam algumas associações litofaciais peculiares e, por este motivo, serão tratadas separadamente. A primeira (Ribeirão do Cinema), não será abordada, devido ao fato de ter sido até o presente, estudada apenas apenas em trabalhos de reconhecimento.

Relações de contato Os contatos externos do cinturão com ortognaisses e milionitos graníticos subjacentes são tectônicos. O limite meridional é marcado por uma zona de transcorrência com contatos subverticalizados, concordantes por efeito de rotação e transposição - Zona de Transcorrência Major Gercino - Porto Belo: ZTMP (Foto B, Prancha 1). Em áreas localizadas da ZTMP, uma trama planar (bandamento milonítico), ligada a uma pretérita fase tangencial $(\mathrm{Sn} / \mathrm{Sn}+1)$, pode ser eventualmente recuperada, a despeito da forte transposição $(\mathrm{Sn}+2)$.

O limite setentrional dá-se através de outra zona de deslocamento lateral, interpretada como uma zona rúptil do Escudo Catarinense (sentido geofísico) por Silva \& Dias (1981). Nela, o cinturão é transposto juntamente com o "embasamento" granito-gnáissico (Zona de Transcorrência Itajaí-Perimbó: ZTIP).

$\mathrm{Na}$ extremidade nordeste, o registro da tectônica tangencial acha-se bem preservado da fase transcorrente superposta. $\mathrm{Na}$ região de Itapema, por exemplo, a seqüência Vulcanossedimentar repousa em contato de baixo ângulo, com terrenos arqueanos, aqui interpretados como uma associação de gnaisses cinzentos bimodais do tipo tonalito-trondhjemito-granodiorito: TTG (Foto A, Prancha 1). Nessa e em outras regiões poupadas dos efeitos da tectônica transcorrente superposta, a natureza tangencial do bandamento milonítico no cinturão fica evidenciada. A superfície Sn encontra-se não raramente redobrada em episódio tardio, que gera dobras isoclinais de pequena e média amplitude, com espessamento das charneiras, planos axiais horizontalizados, e com lineação de estiramento mineral de pequeno caimento paralela ao eixo b (Foto D, Esquema E, Prancha 1). Essas características indicam deformação progressiva, em regime dúctil, não coaxial. Muitas vezes, o forte achatamento e lenticularização paralela aos planos dê empurrão (XY) mascaram essas relações e o registro da deformação tangencial só pode ser identificado em áreas onde uma fase félsica, plutônica ou subvulcânica, sin- a tardi-tectônica serve como marker do evento (Foto A, Esquema B, Prancha 2).

A SEQÜÊNCIA METAVULCANOSSEDIMENTAR RIO DO OLIVEIRA-ITAPEMA Foi caracterizada a partir do reconhecimento em escala 1:25.000, com posterior detalhamento em escala 1:5.000, visando a avaliação de alvos considerados promissores, relativos a depósitos de ouro primário e sulfetos. Inclui expressivo pacote piroclástico, com tufos, lapilitos e brechas de composição máfica. Abrange igualmente termos ultramáficos e mais raramente félsicos, além de sedi- 


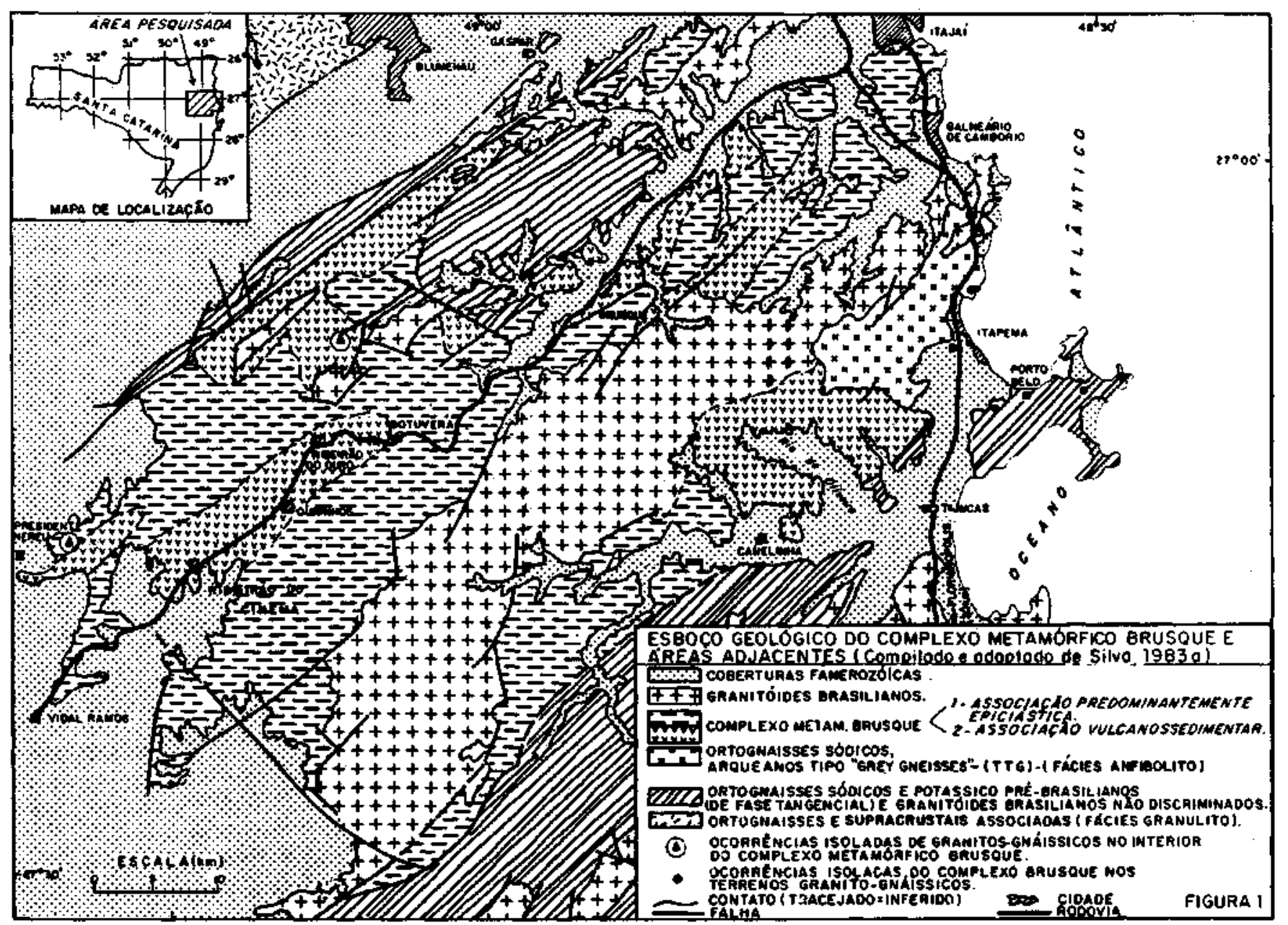

Figura 1 - Mapa de localização e esboço geológico do Cinturão Brusque e áreas adjacentes Figure 1 - Geographical location and sketch-map of metavolcanic-sedimentary Brusque Belt and adjacent terrains

mentos vulcanoclásticos (sentido de Fischer 1961). Fades extrusivas são menos abundantes. Feições vulcânicas remanescentes, em áreas com deformação moderada, incluem texturas vesiculares, texturas vítreas recristalizadas e, ao menos em uma localidade, possível paleoduto, preenchido por brecha máfica. É também relevante a presença de camadas químico-exalativas, com gnaisses cálcio-silicáticos, chertes turmalínicos bandados (turmalinitos), chertes hematíticos bandados (BIFs de fácies oxido), rochas quartzo-gruneríticas (BIFs de fácies silicato) - que representam formações ferríferas do tipo Algoma (sentido de Gross 1965). Entre essas, destacam-se os turmalinitos, com espessuras aflorantes de até $10 \mathrm{~m}$, expostos de maneira descontínua por vários quilômetros (Fig. 2).

O metamorfismo operante foi de baixo a médio grau da fácies anfibolito baixa/xistos-verdes alta, a julgar pelos metassedimentos epiclásticos portadores de andaluzita como polimorfo aluminoso estável, além de estaurolita, relativos à fase de recristalização sin-tangencial (Tab. 1). A cianita ocorre raramente. Essa característica paragenética sugere uma trajetória metamórfica, ao menos em parte, sob condições de baixa $\mathrm{P}$ e alta $\mathrm{T}$, das séries de fácies metamórficas barrowianas de Miyashiro (1973). Nas associações máficas, devido à granulação fina, não foi possível obter uma avaliação precisa do conteúdo em cálcio do plagiocálsio, nem uma determinação do anfibólio, tratado genericamente de "actinolita". Em função disso, as supostas condições de recristalização em médio grau metamórfico são extrapoladas exclusivamente a partir das associações pelíticas, e intercaladas.
Associação metavulcanoclástica Inclui rochas de composição predominantemente máfica e mais raramente ultramáfica e félsica, cuja derivação piroclástica direta ou a partir de retrabalhamento e mistura com material epiclástico, nem sempre é discernível. Foram identificadas três litofácies principais.

\section{BRECHAS VULCÂNICAS MÁFICAS METAMORFIZADAS} São tufos e tufos lapilíticos brechóides, em camadas decimétricas e métricas, de composição máfica, mal selecionados, sem evidências de acamamento interno, em leitos de espessura submilimétrica a métrica. A matriz é fina $(0,01 \mathrm{~mm})$, constituída por epídoto, clorita e actinolita; os litoclastos são angulosos, milimétricos a centimétricos, de composição similar à da matriz. São comuns cristaloclastos de epídoto, actinolita, plagioclásio, albita e quartzo. Essas feições sugerem derivação primária, piroclástica (sentido de Fisher 1961), ao menos em parte, hialoclástica (Foto E, Prancha 1).

METATUFOS MÁFICOS BANDADOS São plagioclasioactinolita anflbolitos, que têm como principais acessórios epídoto, clorita, titanita e magnetita. Caracterizam-se por alternância regular de bandas submilimétricas de actinolita e de plagioclásio, com persistência lateral de centenas de metros, que possivelmente representam o acamamento sedimentar remanescente $(\mathrm{So}=\mathrm{Sn})$ (Fotos $\mathrm{B}, \mathrm{C}$ e D, Prancha 1 , Foto A, Esquema B, Prancha 2). O caráter primário do bandamento é sugerido pela sua persistência mesmo em zonas de baixa deformação, onde camadas básicas, não vulcanoclásticas, in- 

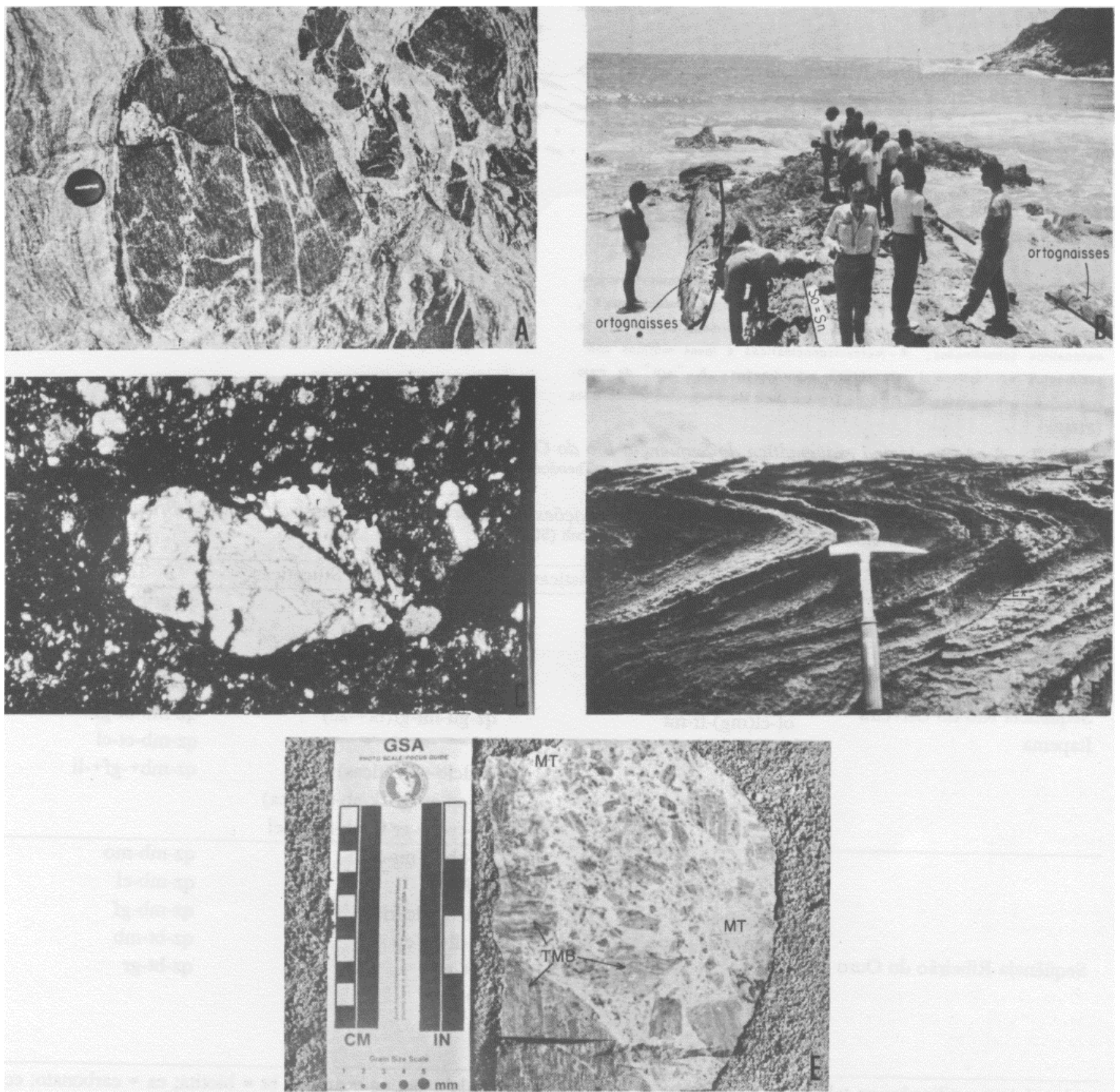

Prancha 1 - A. Embasamento da Seqüência Rio do Oliveira: grey gneisses (TTG) de composição tonalítica (cinza-escuro) e trondhjemítica (cinza-esbranquiçado), com remanescentes xenolíticos de toleitos (preto) caracterizando uma associação bimodal primitiva - BR 101/Camboriú; B. Zona de Transcorrência Major Gercino - Porto Belo (ZTMP): transposição e paralelização de encraves tectônicos (metavulcanoclàsticos) da Seqüência Rio do Oliveira em milonitos graníticos e ortognaisses (Sn+2). Bombinhas; $\boldsymbol{C}$. Seqüência do Oliveira/associação vulcanoclástica máfica: plagioclásio-epídoto-actinolita xisto vulcanoclástico: cristaloclastos do plagioclásio com bordas corroídas e rebordo devitrificado - (r), em matriz escura rica em actinolita (LP) Mesmo local da fotografia B; D. Seqüencia Rio do Oliveiralassociação vulcanoclástica máfica: superfície desenvolvida no episódio tangencial $(S o=S n)$, redobrada progressivamente, com desenvolvimento de fone lineação de estiramento (Lx) paralela ao eixo b. Itapema; $\boldsymbol{E}$. Seqüência do rio do Oliveira/associação vulcanoclástica: brecha constituída por uma mesóstase tufácea, máfica, fina (cinza-claro), composta por epídoto e albita, rica em fragmentos angulosos de tufo máfico bondado (cinza-escuro). A estrutura é interpretada como uma recorrência da atividade vulcanogênica e sugere as proximidades de um paleoduto (brecha de conduto)

Plate 1 - A. Seqüência Rio do Oliveira basement: grey gneisses (TTG) of tonalitic (dark grey) to trondhjemitic (light grey) composition, with tholeitic xenolithes remanents (black) characterizing a primitive bimodal association. Br 101/Camboriu; B. Major Gercino-Porto Belo Transcurrent Zone: paralelization and transposition of xenolithic (basic) enclaves from Sequiência Rio do Oliveira into mylonitic granites and ortogneisses. Bombinhas; $\boldsymbol{C}$. Sequiência Rio do Oliveira/mafic volcaniclastic association: plagioclase-epidote-actinolite banded mafic tuff showing plagioclase crystaloclast with devitrifled rebord (arrowed) and corroded mangin in a black actinolitic matrix - same localy is B; D. Seqüência Rio do Oliveira/mafic volcaniclastic association: tectonic refolded surface associated with the first tangencial episode $(\mathrm{So}=\mathrm{Sn}$ ), progressively folded, with development of a strong b axis paralel stretching lineation $(\mathrm{Lx})$. Itapema; E. Seqüência Rio do Oliveira/volcaniclastic association: breccia composed by a mafic fine grained albite-epidote matrix (light gray) and dismembered angular fragments of former banded mafic tuff (dark gray). This rock association is interpreted as a near vent, recurrent volcanogenic episode (condute breccia) 


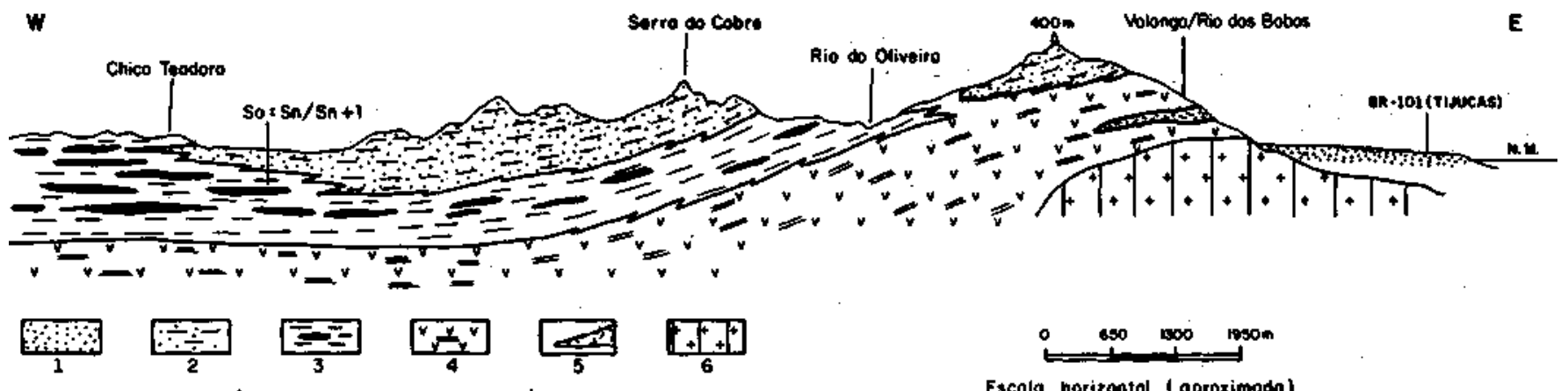

1 - sedimenton duolerndrios; 2 - metoredimentos clósticos (me topelitos com melaranitos subordinodes; 3 - metostadimentos químieos (cálciosilicodticos ) "

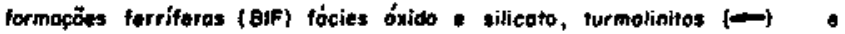
melopelitos subordinodos; 4-metovulconoclósticos tavos móficos com sedimentas epiclósticas (metapelitos) subardinados y 5 - "silt" de matariotito; 6 - orlognaises do Zono de Tramacortheio Major Gercino-Porto Belo (2TMP)

Figura 2 - Seçāo geoldgicà esquemática da Seqüencia Rio do Oliveira - Itapema, no perfil Chico Theodoro-Tjucas Fipure 2 - Sketch-profile of Rio do Oliveirt-ltapetra Sequetice at Chioo Theodoro - Tijucte region (vertical uste ofrited)

Tabela 1 - Assembléias minerais características das associacōes metavulcanossedimentanes do cinturäo Brusque (SC) Thble 1 - Minerals of the metsvulcano-edimentary roclos of the Bruoque belt (SC)

\begin{tabular}{|c|c|c|c|}
\hline & Extrusivas e Vulcanoclásticas & BIFs e Cálcio Silicáticas & Tentgenas \\
\hline \multirow{9}{*}{$\begin{array}{l}\text { Sequência Rio do Oliveira } \\
\text { Itapema }\end{array}$} & ac-pg-ep-ti-(+-cl) & $q z-t u-s f(+-1 i+-m t+-e p)$ & qz-gr-bt-ad \\
\hline & ac-ps-mt & $q z-t \mathrm{u}-s f(+-l i+-c l)$ & qz-gr-bt-ad-cl-mb \\
\hline & ac-pg & $q 2-\mathbf{u}-\mathrm{s} f+-\mathrm{li}+-(\mathrm{fk})$ & qz-bt-ad-si \\
\hline & ac & qz-mit+he & q2-mb-bt-fk \\
\hline & ol-cl(mg)-tr-mt & $q z-g u-m t-g r(b t+-a c)$ & $q z-m b-b t-g r$ \\
\hline & & & qz-mb-ct-cl \\
\hline & ag-ac & (cálcio-silicáticas) & $q z-m b+-g f+-1 i$ \\
\hline & qz-fk-pg-mb & qz-cp-ep-gr-fk-ab-ac-ti(ca) & \\
\hline & & qz-cp-ep-gr-fk-ab-ac-ti+cl & \\
\hline \multirow{7}{*}{ Seqiiência Ribeirăo do Ouro } & ac-cl-ep-mt-ti & qz-ab-cl-mt-ca-li & qz-mb-mo \\
\hline & ac-cl-pg-ep & (BIF?) & $q z-m b-c l$ \\
\hline & $\mathbf{t r}-\mathrm{cl}(\mathbf{m})-\mathbf{t i}$ & (Metacalcários) & $q z-m b-g f$ \\
\hline & $\mathrm{tr}-\mathrm{cl}(\mathbf{m})+-\mathbf{t a}$ & cc-dl-ep-cp & qz-bt-mb \\
\hline & ol-tr & cctep & $\mathbf{q z}-\mathbf{b} t-\mathbf{g} z$ \\
\hline & $\begin{array}{l}a g-p g+-c l+-a c \\
\text { sp-ta }\end{array}$ & dl+ep & \\
\hline & qz-mb-cl-gf & & \\
\hline
\end{tabular}

- Abreviaturas utilizadas na tabela: $\mathrm{ab}=$ albita; $\mathrm{ac}=$ actinolita; $\mathrm{ad}=$ andaluzita; $\mathrm{ag}=$ augita; $\mathrm{bt}=$ biotita; $\mathrm{ca}=\mathrm{carbonato}$; $\mathrm{cc}=$ calcita; $\mathrm{cl}=$ clorita $(\mathrm{m}=$ magnesiana $)$ cp = clinopiroxênio; $\mathrm{ct}=$ clorítóide; $\mathrm{dl}=$ dolomita; ep = epídoto; fk = feldspato potássico; gf = grafita; $g r=$ granada; gu = grunerita; he = hematita; $1 \mathrm{i}=$ limonita; $\mathrm{mb}=$ mica branca mt $=$ magnetita; ol $=$ olivina; $\mathrm{pg}$ $=$ plagioclásio; $\mathrm{qz}=$ quartzo; $\mathrm{sf}=$ sulfetos; $\mathrm{sl}=$ sillimanita; $\mathrm{sp}=$ serpentina; $\mathrm{ta}=$ talco; $\mathrm{t}=$ titanita; $\mathrm{tr}=$ tremolita; tu $=$ turmalina - Outros acessórios comuns a todas as assembléias: $\mathrm{zr}=$ zircão; ap = apatita; mo = minerais opacos

tercaladas, ainda preservam texturas extrusivas. Evidências de derivaçãç piroclástica direta podem ser observadas ao microscópio. E o caso, por exemplo, de cristaloclastos de plagioclásio quebrados com rebordos vítreos (recristalizados), fragmentados supostamente durante o processo de ejeção (Foto C, Prancha 1). Além dessas feições, ocorrem amígdalas preenchidas por epídoto, possivelmente desagregadas durante a deposição da matriz. A ortoderivação é também sugerida pelos altos percentuais de titanita indicando teores elevados de $(\mathrm{TiO}>1 \%)$. A disposição desse mineral em níveis controlados, paralelos ao bandamento composicional, implica em algum controle deposicional e reforça a hipótese da natureza não extrusiva. Algumas intercalações de xistos ultramáficos têm origem ainda discutível. São actinolititos com textura nematoblástica, eventualmente com disposição regular de magnetita em leitos paralelos à direção do bandamento milonítico regional $(\mathrm{Sn})$, possivelmente implicando em controle sedimentar $(\mathrm{So}=\mathrm{Sn})$. Com menor freqüência, ocorrem tremolititos, nos quais, entremeados em matriz fina asbestiforme, foram observados agregados esferulíticos, em forma de rosetas de 2 a $3 \mathrm{~mm}$, sugestivos de cristalização a partir de vidro de composição ultrarnáfica, conforme tem sido caracterizado em algumas seqüências vulcanossedimentares (Gupta et al 1982). Faltam, entretanto, evidencias mais consistentes sobre a derivação vulcanoclástica ou extrusiva. 
Com relação à origem do bandamento composicional prémetamórflco, persistem dúvidas também quanto à possível derivação a partir de: 1. processos primários de deposição em ambiente aquoso, com defloculação e decantação fracionária dos componentes máficos e félsicos, dando origem à sedimentação rítmica; e 2. processos secundários de retrabalhamento de sedimentos vulcanogênicos, com transporte por suspensão turbulenta e deposição em sistemas de correntes de turbidez, com as características genéticas propostas por Bouma (1962). Essa última hipótese parece ser a mais provável para a derivação da maior parte dos tufos bandados. Mesmo nesses casos, a contribuição piroclástica deve ser admitida pela freqüente observação de feições microscópicas como os cristaloclastos de plagioclásio mostrados na fotomicrografia $\mathrm{C}$, prancha 1 .

METATUFOS FÉLSICOS Têm matriz muito fina $(0,01$ $\mathrm{mm}$ ), constituída por quartzo, feldspato, epídoto e sericita, com cristaloclastos submilimétricos de quartzo bipiramidal. Ocorrem em discretos leitos de espessura centimétrica a métrica, intercalados no pacote máfico-ultramáfico. São interpretados como produtos de ejeção piroclástica direta.

Associação extrusiva Componente menor da seqüência, ocorre em discretos leitos com espessura métrica, intercalados na seqüência tufácea, e inclui:

METABASALTOS COM ESTRUTURAS MACIÇAS São reconhecidos mesmo em zonas de alta deformação e taxas avançadas de recristalização. "A mineralogia principal inclui plagioclásio (An 20\%-30\%) + actinolita + epídoto com texturas granoblásticas, nematoblásticas e raramente subofíticas remanescentes. Titanita, clorita, quartzo, apatita e opacos são os acessórios mais freqüentes.

METABASALTOS AMIGDALOIDAIS Têm a mesma composição mineralógica e a mesma textura dos metabasaltos maciços. Porém, apresentam discretos níveis amigdaloidais. Em conseqüência de distintas taxas de deformação finita, as amígdalas apresentam desde formas esféricas até fusiformes. $\mathrm{O}$ diâmetro médio geralmente é da ordem de 5,0 $\mathrm{mm}$ e são preenchidas por quartzo e epídoto (Foto C, Prancha 2).

METAULTRAMAFITOS São xistos ultramáficos compostos exclusivamente por anfibólio actinolítico, tendo como acessórios magnetita e apatita. A actinolita pode ocorrer na forma de pseudomorfos sobre antigos cristais idiomórfícos de piroxênio. Ocorrem ainda tremolititos, tremolita-clorita xistos e olivina-tremolita xistos. Nesse último caso, a olivina exibe zoneamento ígneo preservado, com núcleo enriquecido em magnésio e as bordas em ferro, tratando-se de possíveis sills subvulcânicos.

METARRIODACITOS Constituem discretos derrames e sills félsicos de composição riodacítica. Têm ocorrência muito subordinada. As texturas ígneas preservadas incluem microfenocristais de quartzo bipiramidais, eventualmente com golfos de corrosão bem desenvolvidos, além de feldspato potássico e plagioclásio (An 20 - 35) idiomócficos (Fotomicrografia A, Prancha 3). A matriz é constituída de quartzo, albita, clorita e muscovita. As texturas originais são relativamente bem preservadas devido ao fato de constituírem sills sin- a tardi-tangenciais, que chegam a truncar de forma discreta a foliação Sn impressa nos tufos e derrames máficos, ou nos pelitos encaixantes (Foto E, Esquema F, Prancha 2).

Associação químico-exalativa Além das associações vulcanoclásticas e extrusivas, compõe a seqüência uma terceira categoria de metassedimentos de possível natureza químico-exalativa, constituída predominantemente por gnaís- ses cálcio-silicáticos, associadas aos quais destacam-se formações ferríferas bandadas, com afinidades exalativas.

GNAISSES CÁLCIO-SILICÁTICOS São gnaisses finos, bandados em intervalos milimétricos e submilimétricos, de cores verde/branco e rósea. A granulação varia em torno de 0,1 a $1 \mathrm{~mm}$. A textura é granoblástica a nematoblástica, fortemente xenoblástica. Quartzo, actinolita, titanita e mais raramente epídoto constituem a mineralogia principal. Opacos, apatita e raramente escapolita são os acessórios mais importantes.

TURMALINITOS É a mais característica unidade da seqüência sob diversos pontos: seja como marker estratigráfico, seja como indicador paleoambiental ou, ainda, sob a óptica exploratória. Mesoscopicamente, são caracterizados por uma laminacão regular, em escala milimétrica, dada pela alternância de bandas escuras turmaliníferas e bandas leitosas compostas por quartzo (Foto D, Prancha 2).

Ao microscópio, as bandas turmaliníferas têm espessura média no intervalo de 0,1 a $0,3 \mathrm{~mm}$, enquanto as quartzosas situam-se entre 0,4 e $0,8 \mathrm{~mm}$. Nas bandas claras, o quartzo (metacherte?) forma mosaicos granoblásticos, poligonizados, ou apresenta trama planar, quando se dispõem de maneira orientada segundo a superfície regional $(\mathrm{So}=\mathrm{Sn})$. Nesses casos, os cristais exibem contatos suturados e moderada deformação intracristalina (extinção ondulatória). O tamanho médio dos cristais é da ordem de $0,1 \mathrm{~mm}$. A turmalina apresenta-se em cristais idioblásticos, de cor marrom, com forte zoneamento paralelo do eixo C. Os prismas têm tamanho médio na ordem de 0,1 a $0,3 \mathrm{~mm}$ e exibem arranjo planar preferencial concordante em todas as escalas com a foliação de transposição regional $(\mathrm{So}=\mathrm{Sn})$. Essas características sugerem origem pré-metamórfíca, possivelmente singenética para as bandas turmaliníferas e quartzosas. Sulfetos em cristais xenomórficos ou em agregados irregulares podem envolver os prismas de turmalina e até constituir bandas contínuas e regulares. Nesses casos, há uma passagem gradacional do turmalinito para fácies sulfeto de formação ferrífera. A turmalina foi microscopicamente caracterizada como uma possível variedade de composição intermediária entre a dravita e a schorlita.

Pela importância metalogenética dessas associações, com respeito a depósitos de sulfetos polimetálicos e ouro (singenéticos ou reconcentrados em zonas de cisalhamento), uma breve revisão do problema da gênese dos turmalinitos é pertinente. De há muito tempo, chama a atenção a associação de rochas quartzo-turmaliníferas com diversos tipos de depósitos estratiformes de sulfetos polimetálicos e ouro (além do estanho e tungstênio, entre outros). Apesar desta "coincidência", apenas recentemente a natureza vulcanogênicoexalativa de algumas dessas associações pôde ser satisfatoriamente entendida (Ethier \& Champbell 1977, entre muitos outros). Origem semelhante foi postulada para os turmalinitos da Seqüência Rio do Oliveira, a partir da caracterização de sua natureza sedimentar (estratiforme) e de sua associação com as litofácies cálcio-silicáticas e formações ferríferas (Silva 1983a).

BIFS DE FÁCIES OXIDO, SIUCATO E SULFETO Associados aos turmalinitos e às cálcio-silicáticas, ocorrem discretas intercalações de rochas quartzo-hematíticas, quartzo-magnetíticas e quartzo-gruneríticas, que constituem BIFS do tipo Algoma (sentido de Gross 1965), em pacotes com espessuras decimétricas a métricas.

A SEQÜENCIA METAVULCANOSSEDIMENTAR RIBEIRẤO DO OURO Apesar de desenvolvida no mesmo contexto bacinal da anterior (possíveis rifles), esta seqüência exibe diversas pecularidades litofaciais que a distinguem mês- 

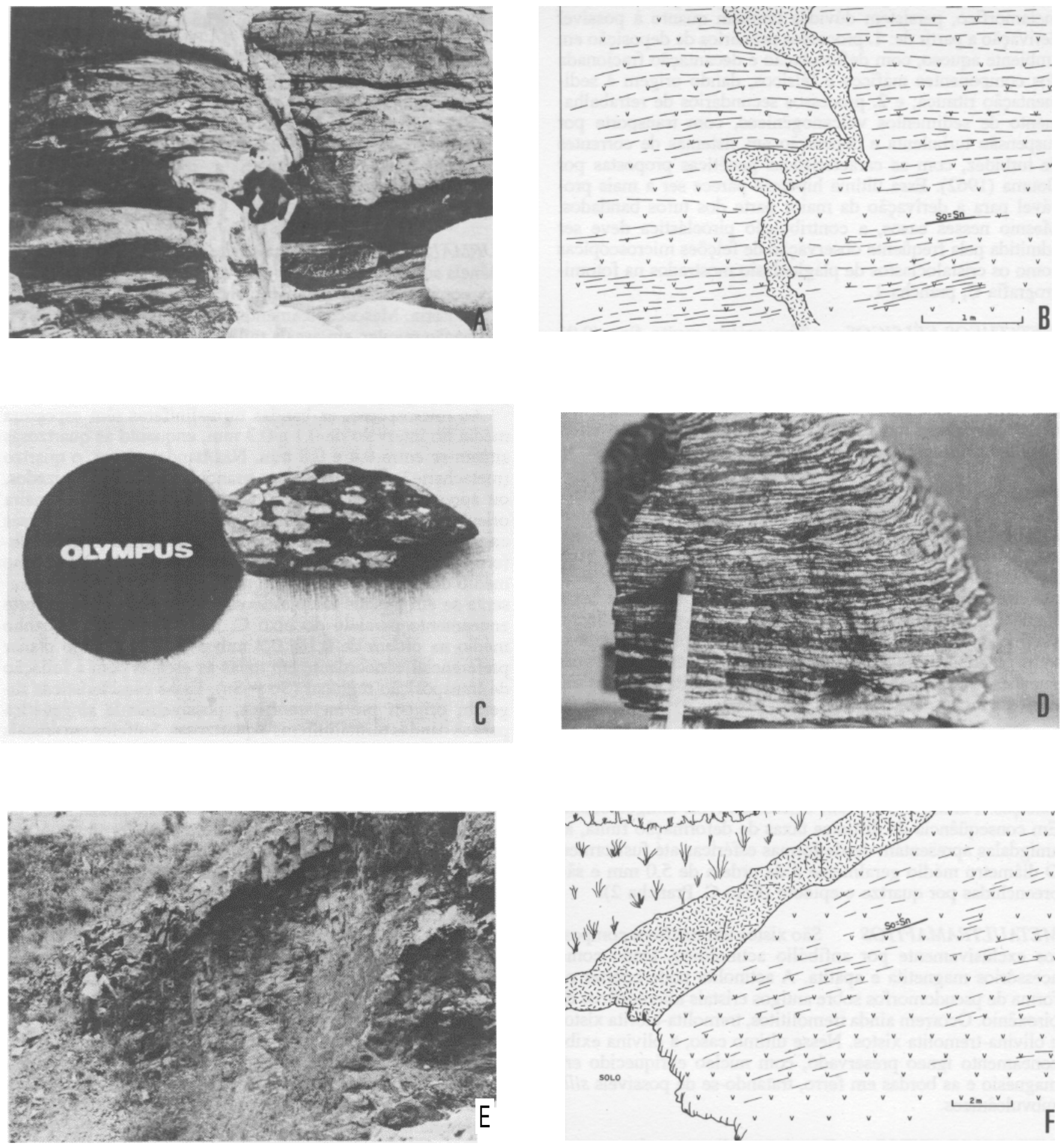

Prancha 2 - A. Seqüência Rio do Oliveira/associação metavulcanoclástica máfica: injeções pegmatóides tardi-tectônicas relativas ao evento tangential Notar o pequeno mergulho $\left(15^{\circ}\right)$ do bandamento $(S o=S n)$. Itapema; B. Reprodução esquemática da fotografia anterior; $\boldsymbol{C}$. Seqüencia Rio do Oliveira/associação máfica: metabasaltos amigdalóides em zonas de média deformação. O discreto achatamento das amígdalas marca o plano XY (Sn). Valongo; D. Seqüência Rio do Oliveiralassociação vulcanoquímica: turmalinito com alternância rítmica de leitos de quartzo (interpretados como metacherte) e leitos turmalínicos (cinza-escuro). O bandamento compositional correspondente à transposição do acamamento sedimentar original $($ So $=$ Sn). Chico Theodore; E. Seqüência Rio do Oliveira/associação metavulcanoclástica máfica: sill félsico tardi a pós-tangencial, truncando a foliação $S o=S n$. Rio dos Bobos; $\boldsymbol{F}$ Reprodução esquemática da fotografia anterior: em destaque o caráter discordante da fase félsica relativa à trama planar (tangential) da encaixante

Plate 2 - A. Seqüência Rio do Oliveira/mafic volcanoclastic association: tardi-tangencial pegmatoid felsic injection. Note the discret $\left(15^{\circ}\right)$ dip of mafic country rock banding $(\mathrm{So}=\mathrm{Sn})$. Itapema; B. Schematic reproduction of photo A (left); C. Seqüência Rio do Oliveira/mafic association: amygdaloidal metabasalts with moderated stretched amygdalas marking the XY plane (Sn). Valongo; D. Seqüência Rio do Oliveira/volcanochemical association: tourmalinites with ritmic alternance of quartz (metachert?) and tourmaline (dark grey) microbands. The compositional alternance corresponds to an original sedimentary (So) layering, now transposed (So - Sn). Chico Theodoro; E. Seqüência Rio do Oliveira/mafic volcanoclastic assotiation: felsic tardi to post-tectonic sill, truncating the (So $=\mathrm{Sn}$ ) plane. Rio dos Bobos; F. Schematical reproduction of photo E (above). Note the discordant nature of the felsic body, relatively to the planar tangential country-rock fabric $(\mathrm{So}=\mathrm{Sn})$ 
mo em um exame superficial. Chama atenção a ausência de turmalinitos, a discreta distribuição de outras associações químico-exalativas, e, a ocorrência de derrames basálticos com estrutura variolítica e localmente almofadada; grauvacas félsicas; metacalcários, metadolomitos; e rochas rítmicas com afinidades turbidíticas, ausentes na Seqüência Rio do Oliveira-Itapema. Suas paragêneses foram reequilibradas sob condições de fácies xisto-verde baixa, constrastante com o grau mais elevado no Rio do Oliveira (Tab. 1).

Embora não existam trabalhos cartográficos em escala apropriada para expressar a variação litológica, a figura 3 mostra uma coluna composta (esquemática) da unidade, na região de Ourinhos.

Os filitos e xistos de baixo grau (zona da clorita) apresentam a mesma evolução ligada ao episódio tangencial. São caracterizados por uma foliação de transposição milonítica $(\mathrm{So}=\mathrm{Sn})$, desenvolvida no evento deformacional progressivo (cisalhamento simples, dúctil). Essa superfície encontra-se freqüentemente redobrada progressivamente em um segundo incremento deformacional registrado em mesodobras isoclinais fechadas, de envergadura decimétrica $(\mathrm{Dn}+1)$.

O principal componente é uma espessa associação clastoquímica de calcários dolomíticos e dolomitos cinzentos, grafitosos de ambiente euxínico, expostos por dezenas de quilômetros, com espessuras aparentes de dezenas de metros. São calcários maciços ou com intercalações decimétricas a métricas, de grande expressão lateral, de tufos máficos, xistos pelíticos e metarritmitos - estes com afinidades turbidíticas. A principal associação vulcânica intercala-se nesse pacote pelito-carbonático. Afigura 3 é uma tentativa de representação esquemática da seqüência.

A estimativa de espessura tectônica aflorante na região de Ribeirão do Ouro é da ordem de 1.000 a 1.200 m, incluindo os pacotes vulcanossedimentares e terrígenos.

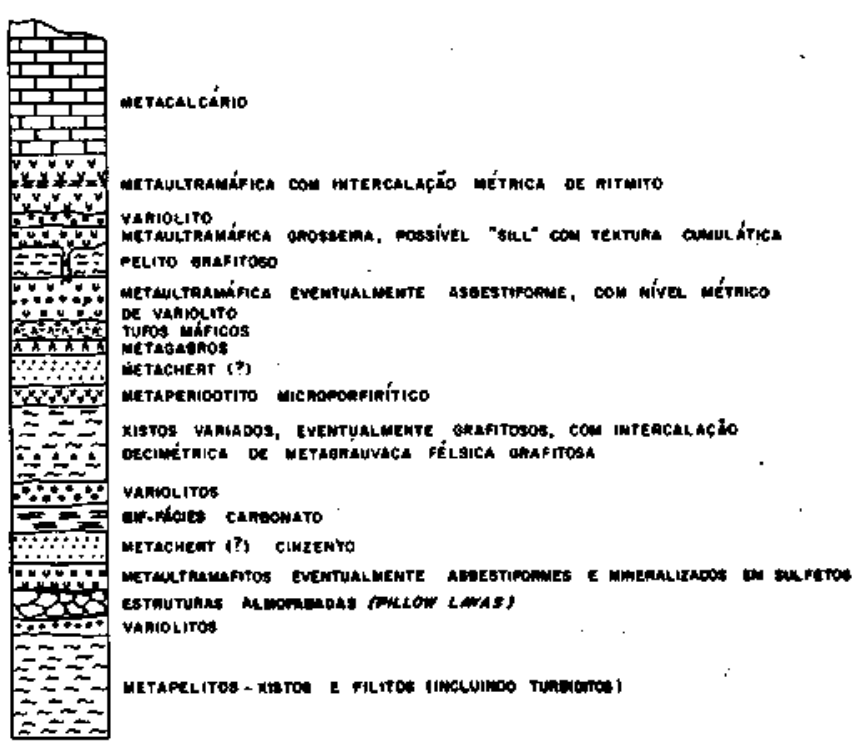

Figura 3 - Coluna esquemática composta (fora de escala) da Seqüencia Ribeirão do Ouro. A trama ligada ao evento tangencial é co-planar com o bandamento composicional $S o=S n$ (espessura tectônica exposta na região de Ourinhos: aproximadamente 1.000 a $1.200 \mathrm{~m}$ )

Figure 3 - Sketch-profile showing Ribeirão do Ouro Sequence. Planar fabric related to tangencial event is coplanar with the compositional layering $(\mathrm{So}=\mathrm{Sn})$. Estimated tectonic thickness in Rio do Ouro vicinities, aproximately 1.000 to $1.200 \mathrm{~m}$ (vertical scale omited)

A associação vulcanossedimentar inclui xistos máficos e ultramáficos, tremolititos e albita-actinolita xistos, possíveis equivalentes dos tufos bandados da Seqüência Rio do Olivei-
ra-Itapema. Apresentam as mesmas evidências de derivação vulcanoclástica, inclusive níveis preferenciais de concentração de titanita, reflexo de controle deposicional primário. Intercalações métricas a decamétricas de pelitos grafitosos, quartzitos de derivação incerta, filitos e metaturbiditos são comuns. Em superfícies adequadamente expostas e preservadas da deformação tangencial é possível observar, em diversas estruturas sedimentares primárias preservadas, marcas de onda, estratificação paralela e oblíqua de pequeno porte, acamamento gradacional e rítmico. Intercalações básicas ou mesmo peridotíticas, com feições vulcânicas/hipabissais remanescentes (texturas microporfiríticas e cumuláticas), são observadas localmente em zonas de baixo strain,

Merecem destaque devido à sua importância como marcadores estratigráficos e indicadores paleoambientais alguns litótipos vulcânicos e sedimentares, entre os quais se destacam:

Metabasaltos variolíticos A designação variolítica é empregada, no sentido restrito, de acordo com Gélinas \& Brooks (1974) e Gélinas et al (1976), para lavas portadoras de níveis ricos em corpos esféricos de diâmetro milimétrico a centimétrico, eventualmente coalescentes (Fotos B e D, Fotomicrografia C, Prancha 3 ) os quais - relativos à matriz afanítica - apresentam composição distinta, refletida na coloração mais clara e no relevo positivo em superfícies intemperizadas (Foto B, Prancha 3). Desde a sua descoberta (Silva 1983b), constituíram-se na primeira e, até o presente, na única ocorrência de variolitos (stricto sensu) descrita fora do Cráton São Francisco em Minas Gerais (Fortaleza de Minas, Teixeira \& Danni 1979); Pihum-Hi (Pinheiro 1980) e Rio das Velhas (Ladeira 1981), ou na Bahia, no Greenstone Belt do Rio Itapicuru (Silva 1984). Os derrames têm espessuras discretas, decimétricas a métricas, com expressão lateral de centenas de metros. São constituídos exclusivamente por uma paragenêse de substituição metamórfica: tremolita-actinolita, epídoto, clorita e carbonato. Raramente preservam composições primárias, devido às alterações hidrotermais associadas ao processo de erupção submarina e a alterações metamórficas superpostas.

A origem dessas estruturas e de outras estruturas quenched têm sido atribuídas à extrusão em ambiente subaquoso, com conseqüente resfriamento rápido (quenching) de dois magmas com composição ao menos levemente contrastante, imisciveis previamente à extrusão (Silva 1983b).

Microscopicamente, as variolas são subarredondadas a elipsoidais, com tamanho médio do eixo maior entre 3 e 25 $\mathrm{mm}$ (Fotomicrografia C, Prancha 3 ). As texturas são granoblásticas, constituídas por finos agregados de epídoto-carbonatos-tremolita/actinolita-clorita-opacos e quartzo, este último em porcentagens próximas à unidade. A matriz é composta por agregados feltrosos de prismas de tremolita-actinolita, com comprimento médio na ordem de $0,01 \mathrm{~mm}$, localmente com texturas de fluxo primário preservadas. Além desse componente principal, que perfaz de 60 a $75 \%$ do volume total, ocorrem ainda carbonato $(5$ a $10 \%)$, clorita $(5$ a $10 \%)$, epídoto (2 a $10 \%)$, minerais opacos (5 a $10 \%)$ e quartzo $(<1 \%)$.

A composição ultramáfica da matriz, além das texturas variolíticas - diagnosticas de resfriamento rápido subaquoso (quenching) - sugeriam, na ausência de parâmetros litoquímicos e por correlação com as demais ocorrências brasileiras, possíveis afinidades com derrames komatiíticos (Silva 1983b). Essa hipótese apenas recentemente está sendo testada por litogeoquímica (em execução pela Superintendência Regional de Porto Alegre da CPRM). A análise de duas dezenas de resultados de óxidos, elementos traços e elementos terras raras - por se encontrar em fase inicial de tratamento - ainda não permitiu um diagnóstico preciso da natureza geoquímica (W. Wildner, informação pessoal). Entretanto, as afinidades komatíticas sugeridas microscopicamente pela natureza ultramáfica podem ser descartadas devido aos teores normais 

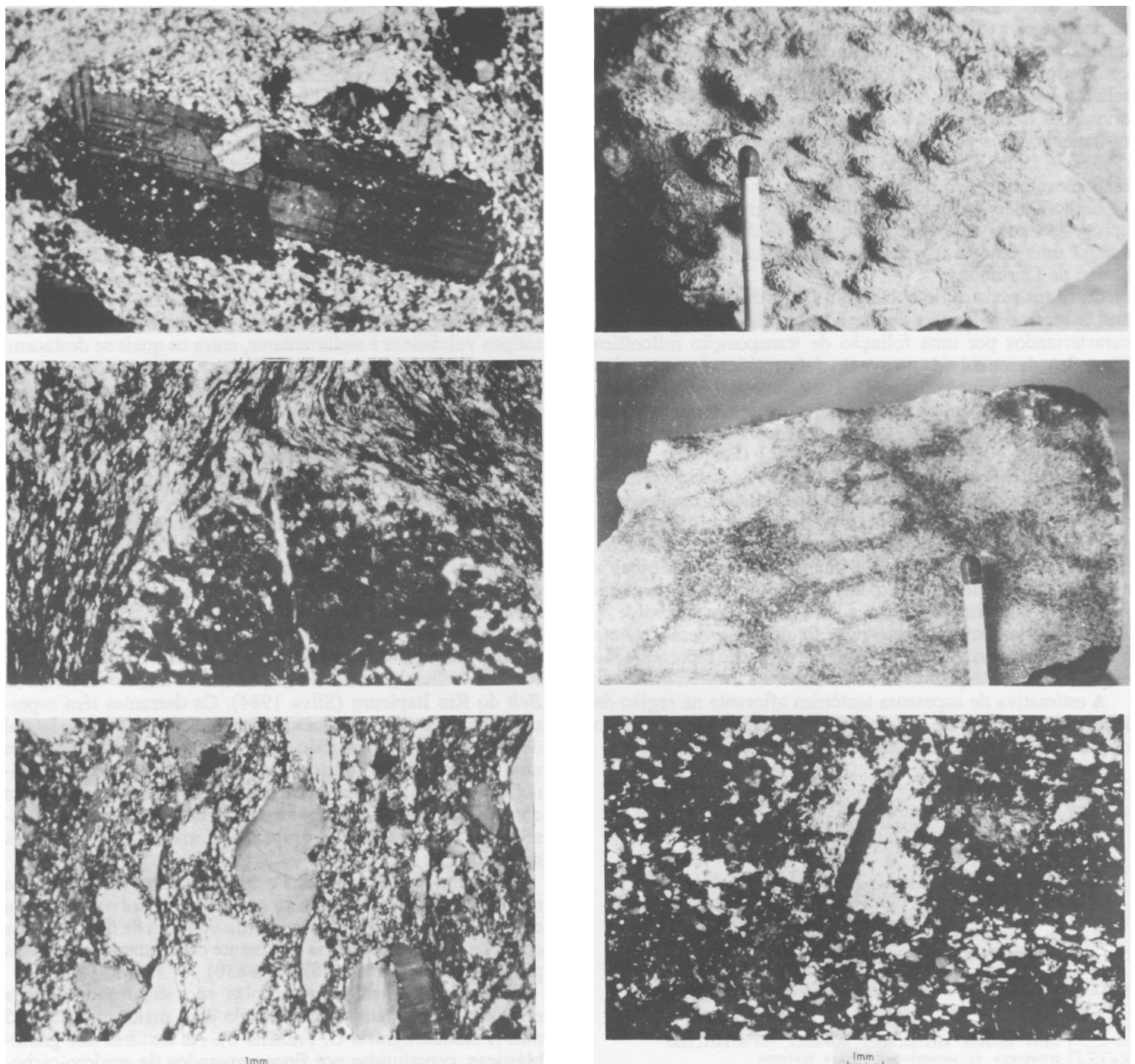

Prancha 3 - A. Seqüência Rio do Oliveira/seção delgada do sill félsico da foto E, prancha 2: fenocristal idiomórfico de oligoclásio em matriz microfelsítica sugerindo composição riodacítica. Os efeitos metamórficos são restritos à recristalização da sericita na matriz, com discreta trama planar (LP); B. Seqüência Ribeirão do Ouro/metabasalto variolítico: relevo positivo das variolas relativo à matriz em superfície intemperizada, diagnóstico de composição petrográfica contrastante. Ribeirão do Ouro; C. Seqüência Ribeirão do Ouro/seção delgada da amostra anterior: paragênese de alteração do variolito, albita tremolita/actinolita - carbonato - clorita. A matriz (ma) é mais rica em tremolita relativamente às variolas. O contorno esférico da variola e seu contato brusco com a matriz são reflexo da composição contrastante e do resfriamento rápido (quenching) (LN); D. Seqüência Ribeirão do Ouro: metabasalto variolítico com coalescência de variolas. A coloração mais clara dessas na a matriz é reflexo da composição mais básica dessa última; E. Seqüência Ribeirão do Ouro: grauvaca félsica com matriz metapelítica, grafitosa, e cristaloclastos de quartzo, com golfas de corrosão. Ribeirão do Ouro. (LP); F. Seqüência Ribeirão do Ouro: "xisto magnético" com megacristal de albita geminada, em matriz fina de quartzo - albita - clorita - magnetita carbonato de ferro, interpretado como alteração hidrotermal de lavas básicas (LP). Estrada para Ribeirão da Areia

Plate 3 - A. Seqüência Rio do Oliveira: thin section from felsic sill of photo E, plate 2 (above) - idiomorphic oligoclase phenocrystal (pg) into a microfelsitic, probable riodacitic matrix. Incipient metamorphic effects like sericite recristalization after plagioclase and discrete sin-tectonic planar fabric may be seen (X pol.); B. Seqüência Ribeirão do Ouro/variolitic metabasalts: the varioles (va) have positive relief relatively to matrix (in intemperized sufaces), suggesting compositional contrast. Ribeirão do Ouro; C. Seqüência Ribeirão do Ouro/variolitic metabasalts variolite alteration paragenesis: albite - tremolite - epidote carbonate - chlorite. Matrix (ma) is more tremolitic relatively to varioles. The spherical shaped varioles and their sharp contacts with the matrix may be due to contrasted petrographical composition (immiscibility) and rapid cooling (quenching), (=light). Same locality as in B; D. Seqüência Rio do Oliveira/variolitic metabasalt: coalescentes varioles. The lighter gray varioles tonality relatively to the matrix colour suggests more basic composition of the latter. Same locality as C; E. Seqüência Ribeirão do Ouro: felsic greywacke with graphitic metapelitic matrix. The quartz cristaloclasts (qz) are corroded, suggesting volcanic precedence. Ribeirão do Ouro; F. Seqüência Ribeirão do Ouro/ "magnetic schist" geminated albitic plagioclase in magnetite-chlorite-iron carbonate transformation matrix, prelliminarly interpreted as hydrotermal alteration of basic flows. Ribeirão da Areia road 
em $\mathrm{MgO}$ dos termos máficos e ultramáficos. Além das variolas, possíveis estruturas de fluxo primário são eventualmente observáveis na matriz.

Metabasaltos com estruturas em almofadas Algumas intercalações metabásicas apresentam estruturas possivelmente primárias, com perfil elipsoidal bastante regular, em seções paralelas ao plano YZ do elipsóide deformacional, com eixo maior de expressão decimétrica, as quais foram preliminarmente interpretadas como lavas almofadadas por Vial (1986). Não somente em função da deformação como também das intensas alterações hidrotermais - ligadas a processos de espilitização em assoalho oceânico - a matriz e o suposto material interpillow não são de fácil reconhecimento. Observações posteriores mostraram que, enquanto algumas estruturas são constituídas por basalto maciço, outras exibem uma capa variolítica, característica comum em lavas em almofadas. Dessa forma, a natureza almofadada destas lavas pode ser assumida neste trabalho.

Metagrauvacas félsicas São também destacáveis discretos leitos de grauvaca félsica, com matriz pelítica grafitosa e abundantes cristaloclastos de quartzo. Ao microscópio, a derivação de fonte vulcanogênica (félsica) dos profiroclastos (antigos cristaloclastos) é evidenciada pela presença de golfos de corrosão (Fotomicrografia E, Prancha 3).

\begin{abstract}
Albita-carbonato-quartzo-clorita xistos São xistos de coloração verde-acinzentada, que, por efeito do intemperismo, adquirem tonalidade ocre característica, devido à alteração do carbonato de ferro. Ao microscópio, a textura é granoblástica e a granulação é de fina a média; a composição mineralógica é representada por clorita $(40 \%-45 \%)$, quartzo (30\%-35\%), magnetita limonitizada $(5 \%-10 \%)$, carbonato de ferro alterado $(5 \%-10 \%)$ e albita $(5 \%-10 \%)$ (Fotomicrografia $\mathrm{F}$, Prancha 3). Esses xistos têm gênese controversa; numa primeira aproximação, foram interpretados como possíveis formações ferríferas de fácies silicato/carbonato. Entretanto, outras hipóteses genéticas mais prováveis devem ser consideradas, como a alteração hidrotermal de derrames básicos ou mesmo sills intrudidos na seqüência. As espessuras dessas intercalações são de decimétricas a métricas.
\end{abstract}

CARACTERIZAÇÃO PALEOAMBIENTAL O expressivo pacote elástico, terrígeno, que inclui turbiditos (indicativo de fonte continental), associado a erupções subaquosas máfico-ultramáficas é mais importante constraint na análise da evolução bacinal. $\mathrm{O}$ desenvolvimento de uma bacia intracontinental com as dimensões hoje preservadas implica em processo de extensão, afinamento e rifteamento, com envergadura suficiente para fragmentar e, possivelmente, separar blocos ou mesmo fragmentos continentais, e gerar os canais de ascenção dos magmas mantélicos. $\mathrm{O}$ não-reconhecimento dos exalitos de fundo oceânico e dos derrames subaquosos variolíticos e almofadados (espilitizados) tem levado alguns autores à preconização de modelos colisionais do tipo "A" para a região (Basei 1985). Entretanto, a presente caracterização sugere que o rifte possa ter efetivamente conduzido à geração de assoalho oceânico. Atectônica tangencial responsável pelo desenvolvimento de dobramentos recumbentes e de nappes associadas ao forte metamorfismo poderia sugerir mecanismos convencionais de subducção (tipo "B"). No entanto, as características paleobacinais, a trajetória metamórfica, sob regime de alta $\mathrm{T}$ e baixa $\mathrm{P}$, a ausência de xistos-azuis e de melanges tectônicas vulcanossedimentares ainda são argumentos restritivos às tentativas de reconstituição de fragmentos de crosta oceânica, similares aos ofiolitos modernos, conforme especulações de Issler (1982), sobre o desenvolvimento da "Faixa Tijucas" no Rio Grande do Sul e Santa Catarina. A ausência de registro de vulcanismo an- desítico ou toleítico de baixo-K e de plutonismo cálcio-alcalino do tipo ' $T$ '-cordilheirano no interior do cinturão são fatores restritivos a comparações com o registro de arcos insulares modernos.

Os sistemas deposicionais dominantemente marinhos - controlados por sedimentação elástica imatura: turbiditos, grauvacas potássicas, sedimentos vulcanoclásticos associados a derrames subaquosos variolíticos, sills máficos e ultramáficos, com interflows ortoquímicos incluindo BIFs - caracterizam o ciclo vulcanossedimentar inicial. Esta fase possivelmente precedeu a deposição de um espesso pacote pelítico-psamítico (não abordado neste trabalho), que era anteriormente interpretado como única associação litofacial da bacia. A grande variação composicional dos pacotes sedimentares e o vulcanismo sin-deposicionais indicam mudança rápida de fácies, em fossas profundas, controladas por falhamentos de bordo. A sedimentação terrígena associada implica em contribuição continental (granítica). A deposição de sedimentos ortoquímicos e BIFs sugere períodos de quiescência, intenso fluxo térmico típico de regiões abissais, além de condições anóxicas, da mesma forma que as intercalações de pelitos grafitosos. A escassez de basaltos vesiculados, sugestivos de erupção em águas rasas (Dunlop \& Buick 1981), reforça a possibilidade de extrusão em fossas profundas, da mesma forma que a eventual preservação de estruturas primárias (não destruídas por ação de ondas e marés) nos pacotes turbidíticos.

Discretas camadas de conglomerados e microconglomerados, descritos na extremidade nordeste do cinturão (Silva \& Dias 1981), poderiam relacionar-se a uma litofácies fluvial, mas os registros ainda são regionalmente restritos e pouco conhecidos. A composição básica da maior parte dos depósitos vulcanoclásticos - possivelmente derivados de extrusões submarinas -, indica soerguimento, exposição subaérea desses pacotes e atuação de processos intensos e rápidos de erosão, sucedendo à exposição de pilha vulcânica, com posterior deposição em sistemas de correntes de turbidez.

Com base nessas características, as duas seqüências vulcanossedimentares refletiriam uma evolução bacinal ligada à extensão crustal; correspondem aproximadamente ao registro da "fase rifte matura" - na classificação dos riftes proterozóicos da Austrália (Beardsmore et al. 1988). A ausência de vulcanismo félsico subaéreo, de depósitos vulcanoclásticos fluvio-marinhos e sobretudo de depósitos de leques continentais tectonicamente controlados (de bordo de grábens), não permitiu a identificação da fase de "rifte precoce" dos autores supra referidos. A "fase de afundamento" ou de relaxamento termal encontra equivalência no espesso pacote terrígeno pelítico-psamítico, depositado em ambiente marinho raso, o qual, em trabalhos anteriores, sugeria afinidades "plataformais" ao cinturão.

A atual forma alongada do cinturão pode refletir o padrão linear original da bacia, embora a tectônica tangencial (colisional), o aloctonismo e a tectônica transcorrente superposta não mais permitam a reconstituição dos limites originais e a comprovação dessa hipótese.

Conseqüências Nesse cenário, incompatível com um desenvolvimento em bacias intracratônicas rasas ou plataformais (sem ou com discreto relevo marginal positivo), pode ser descartada a evolução Brusque do contexto de uma margem continental passiva da região de dobramentos do Sudeste/Cinturão Dom Feliciano (ao contrário do preconizado por Hasui et al 1975, Fragoso-César 1980, Fragoso-César et al 1982, Basei 1985, Basei \& Teixeira 1987, Mantovani et al 1987, entre outros). Podem ser questionadas, também interpretações baseadas na similaridade da seqüência com uma cunha sedimentar associada a regime de arcos insulares, cujo com ponente vulcânico teria sido erodido (Trainini et al 1978). A ausência de vulcanismo e sedimentação vulcanoclástica de composição intermediária (andesítica) comprome- 
tem interpretações baseadas na evolução em um sistema de arco insular.

É possível que o pacote pelítico da fase de relaxamento termal, muito mais expressivo na distribuição geográfica que as seqüências vulcanossedimentares aqui detalhadas apresentam, tenha contribuído para a formulação de modelos pouco adequados ao entendimento da evolução global do cinturão. E o que se deduz, por exemplo, de trabalhos nos quais a evolução paleobacinal da Seqüência Ribeirão do Ouro foi interpretada como "ambiente sedimentar marinho agitado (sic), com retrabalhamento de caráter sublitorâneo" (Basei 1985). Nesse contexto, a síntese das características das associações vulcanossedimentares aqui revisadas, embora não tenha a pretensão de ser definitiva, fornece novos elementos para uma discussão mais consistente.

$\mathrm{O}$ interacamamento múltiplo entre os metassedimentos e meta vulcânicas e a ausência de zonação vertical de termos intrusivos/extrusivos ou de grau metamórfico baixo/alto são argumentos críticos para a distinção de seqüências associadas a riftes continentais de autênticos fragmentos de assoalhos oceânicos (Grooves \& Batt 1985). Nessa mesma direção, apontam o regime de baixa $\mathrm{P}$ e alta $\mathrm{T}$, a ausência de associações metamórficas de fácies xistos-azuis, de toleítos de baixo $\mathrm{K}$ e melanges vulcanossedimentares, além da contribuição continental do principal pacote elástico. Assim, o modelo defendido no trabalho de Issler (1982), no qual a associação vulcanossedimentar é interpretada como uma seqüência ofiolítica, necessita de outros elementos comprobatórios. Da mesma maneira, a possibilidade das diversas bacias similares ao Brusque, no Bloco Paraná, terem evoluído em sistemas de retro-arcos mesoproterozóicos (Soares 1988) - devido à escassez de informações litoquímicas - ainda não pode ser totalmente assumida em Santa Catarina.

Como decorrência, mecanismos de colisão tipo "B", superpostos à propagação de riftes intracratônicos, embora insuficientemente caracterizados, não podem ser descartados para a região - especialmente em uma análise integrada com o registro proterozóico de outros segmentos do Bloco Paraná e com a borda ocidental do continente africano -, conforme será posteriormente discutido.

A natureza não-magnesiana dos derrames varilíticos contraria suas supostas vinculações a derrames komatíticos, embora as afinidades genéricas do Cinturão Brusque com associações de riftes (proterozóicos) "similares a greenstone belts", preconizadas por Silva \& Dias (1981), tenham sido confirmadas (Codie 1990). Finalmente, ainda, não pode ser descartada a hipótese de que a espessa seqüência terrígena, "plataformal", possa constituir-se em uma unidade alóctone, mais jovem, tectonicamente embricada na associação vulcanossedimentar. Nesse caso, sua caracterização como fragmentos de terrenos suspeitos, relativamente à evolução eoproterozóica, do restante do cinturão, merece ser adequadamente testada.

PLUTONISMO GRANÍTICO As relações entre as principais fases de plutonismo granitóide e os eventos tectonotermais proterozóicos ainda não estão bem estabelecidas. Entretanto, em quase todos os trabalhos de integração já executados são evidenciadas quatro fases principais: 1. plutonismo pré- a sin-tangencial/granitóides do tipo "I": é a fase mais precariamente estudada. Esta fase foi identificada na forma de discretos sheets de homblenda gnaisses tonalíticos, concordantes com a trama planar tangencial das supracrustais, ou em corpos situados nas bordas externas do cinturão, onde são transpostos pela deformação transcorrente. A presença de homblenda modal sugere afinidades com os granitóides do tipo "I" de Chappell \& White (1974). Afalta de tratamento litoquímico não permite avançar em sua caracterização ao ponto de se testar a possibilidade de sua relação como uma associação cálcio-alcalina cordílheirana (expandida), ou não;
2. plutonismo pós-tangencial interno ao cinturão: inclui as denominadas suítes Valsungana e Guabiruba, de composição quartzo-monzonítica a sienogranítica e características químicas e isotópicas que levaram Basei (1985) a classificá-las como do tipo "S". As idades de cristalização obtidas em diagramas isocrônicos $\mathrm{Rb}-\mathrm{Sr}$ (rocha total) e pelo método $\mathrm{U}-\mathrm{Pb}$ (em zircão) situam-se no intervalo $620 \mathrm{Ma}-650 \mathrm{Ma}$ (Basei 1985) e as idades-modelo $\mathrm{Nd}$, referentes à diferenciação do material precursor, em torno de $2.000 \mathrm{Ma}$. Embora não se conheçam possíveis relações entre os eventos tectônicos envolvidos no segundo ciclo de rifteamento (Itajaí) e os mecanismos responsáveis pela geração desses fundidos intracrustais, as idades compatíveis podem significar relações de causa e efeito a serem pesquisadas e estabelecidas em futuros trabalhos;

3. plutonismo pós-tangencial/granitos do tipo "I"- caledonianos: inclui a maior parte do volumoso plutonismo externo ao Cinturão Brusque, genericamente designado de Suíte Pedras Grandes. Foi caracterizado como uma associação cálcio-alcalina do tipo "I"- caledoniana no trabalho de Basei (1985). As idades de cristalização - atribuídas à refusão de diversificados níveis crustais do embasamento -, situam-se entre 520 Ma e $620 \mathrm{Ma}$. As idades de diferenciação mantélica dos protólitos situam-se no intervalo de 1.300 Ma a 1.700 Ma. Embora a maior extensão desse plutonismo não apresente relações espaciais com os remanescentes dos riftes Brusque e Itajaí, seu caráter distai não exclui uma possível ligação. É possível prever um controle dos mecanismos de fusão crustal pelas mesmas anomalias mantélicas indutoras dos processos de extensão e afinamento crustal, durante o período Itajaí, conforme parecem indicar as idades Rb-Sr brasilianas desses granitóides. As idades-modelos Nd no intervalo $1.700 \mathrm{Ma}-1.300 \mathrm{Ma}$ sugerem ligação entre os fenômenos de diferenciação dos magmas mantélicos (precursores da suíte) com as anomalias termais da fase rifte ou da fase compressional Brusque;

4. plutonismo pós-tangencial/granitos do tipo "A": são plútons epizonais associados aos riftes modernos (Itajaí - Campo Alegre) que podem ser coletivamente relacionados à Suíte Subida; são riebeckita-arfvedsonita granitos e sienitos, peralcalinos, caracterizados como do tipo "A" no trabalho de Basei (1985). Embora genericamente sejam designados como anorogênicos (e.g. Silva \& Dias 1981, Kaul et al 1982, Basei 1985, Issler \& Freire 1985), as características petrogenéticas desse tipo de granitóides, ligadas à fusão seca na base da crosta continental granulítica, exige a interveniência de consideráveis anomalias térmicas e underplating básico na base da crosta continental, para tornar operativos os fenômenos anatéxicos (Clemens et al 1986). Mais uma vez é necessário relacionar o possível mecanismo indutor das fusões parciais aos processos globais de rifteamento Itajaí - Campo Alegre. As idades no intervalo $500 \mathrm{Ma}$ a $540 \mathrm{Ma}$ (Basei 1985), para este evento pluto/vulcânico, são compatíveis com estas inferências.

POSSÍVEIS CORRELAÇÕES As associações vulcanossedimentares Brusque têm recebido as mais diversas e contrastantes interpretações, relativas a possíveis origens e evolução, que na maior parte dos casos, são conflitantes com os resultados sintetizados no presente trabalho. Face ao suposto caráter plataformal, sua correlação direta tem sido preconizada com o Grupo Açungui nos estados do Paraná e São Paulo, às Formações Cerro dos Madeiras (Grupo Porongos) e Maricá no Rio Grande do Sul, ao Grupo Lavalleja no Uruguai, com o Grupo La Tinta na Argentina e, até, com o Grupo Bambuí (Fragoso-César et al 1982, p. 4). Mesmo em trabalhos recentes que já reconhecem o caráter vulcanossedimentar aqui detalhado, o cinturão é correlacionado, entre outros, ao Grupo Araxá (Soares 1988).

A inexistência de qualquer programa sistemático de correlação entre as diversas seqüências vulcanossedimentares e seu 
arcabouço geotectônico desaconselha as tentativas de se estabelecerem comparações imediatas. Entretanto, ao menos para o Bloco Paraná (sentido de Soares 1988), alguns elementos de comparação podem ser preliminarmente levantados.

No Rio Grande do Sul, as associações vulcanossedimentares do bloco oriental do Escudo Sul-Rio-Grandense, pertencentes ao Grupo Porongos (sentido de Fragoso-César 1980), são rotineiramente correlacionadas ao Brusque. Essa tradição remonta à definição da Faixa Dobrada Tijucas (Hasui et al 1975). Algumas seqüências pertencentes ao Porongos podem apresentar elementos de correlação com o Cinturão Brusque, conforme tem sido revelado em trabalhos recentes desenvolvidos pelo Programa Levantamentos Geológicos Básicos do Brasil (Orlandi 1989, informação pessoal). Entretanto, não é menos verdade que também no bloco ocidental, outras seqüências (Complexo Vacacaí) - seja nas proximidades do Complexo Granítico de Caçapava do Sul ou em outras regiões - podem igualmente exibir associações litofaciais comparáveis. Na ausênciade um trabalho sistemático de correlação entre as duas áreas, não existem, no momento, possibilidades de se fazer julgamento mais elaborado.

No pré-cambriano paranaense, encontram-se evidências de convergência na comparação Brusque/Complexo Setuva (Formação Perau) do Mesoproterozóico (sentido Soares 1988), especialmente com base em: I associação pelítico-psamítica; II associação vulcanossedimentar predominantemente máfica, tufácea carbonática, incluindo exalitos femferos e manganesíferos; e, finalmente,III. associação terrígena imatura, grauvaqueana, de leques submarinos e turbidíticos.

Mesmo havendo essa identidade entre as associações litológicas, paleoambientais e as condições metamórfico-deformacionais, em Santa Catarina, como foi anteriormente discutido, não é possível assumir os mesmos elementos organizacionais delineados no trabalho de Soares (1988). A caracterização de um retroarco mesoproterozóico e sua evolução por meio de evento colisional do tipo arco-continente exige, ainda, muito trabalho adicional para permitir melhor juízo. Outro elemento que evidencia as atuais dificuldades de entendimento da evolução em ambos os Estados é dado pela denominada Seqüência Cachoeira. Esta tem sido considerada como uma associação de "xistos do embasamento pré-Setuva" (Soares 1988), de idade arqueana (Complexo Rio das Cobras de Lima \& Lopes 1985); o segmento catarinense deste complexo tem sido cartograficamente discriminado como uma extensão do Complexo Brusque devido à estreita relação entre os mesmos.

No Estado de São Paulo, dispõem-se de bons referenciais de comparação com a Formação Perau do Grupo Setuva na região de Pilar do Sul, com base na similaridade entre diversas litofácies características da seqüência vulcanogênico-exalativa, incluindo turmalinitos (Stein et al 1986). Na região de Ivaporunduva, no Vale do Ribeira, ainda no Grupo Setuva, e no Complexo Embu, na região de Taiaçupeba, proximidades de Mogi das Cruzes, em associações vulcanossedimentares portadoras de intercalações estratiformes de turmalinitos - as quais foram recentemente identificados - são igualmente encorajadoras para futuros trabalhos de correlação. Entretanto, pelos dados atualmente disponíveis, é no Grupo Serra de Itaberaba (Juliani et al 1986) que se reconhece um número mais significativo de elementos de identificação com a Seqüência Rio do Oliveira - Itapema. Esses elementos correspondem à paleogeografia e à evolução tectônica homólogas, relacionadas à abertura, preenchimento e fechamento de um sistema rifte com idade de 1.800 Ma para o vulcanismo félsico (Juliani et al 1986). As duas unidades exibem particular correspondência, tanto nas associações petrográficas e litofaciais (incluindo rochas vulcanoclásticas máficas, félsicas, cálcio-silicáticas e turmalinitos exalativos), quanto no grau metamórfico (médio grau) e, relativamente, nos mecanismos e sucessão deformacional (ver Juliani et al 1986, para fins comparativos).
Mesmo sem a pretensão de abordar a totalidade dos cinturões vulcanossedimentares do Bloco Paraná, mas apenas para retomar um aspecto da interessante síntese de Soares (1988), vale aqui destacar alguns pontos. Da mesma forma que a existência de um pacote carbonático tem levado, em análises mais simplistas, a uma correlação Brusque/Açungui - Bambuí, a presença de importante seção terrígena marinha (pelítico-psamítica) pode conduzir a comparações indesejáveis de parte da seqüência Brusque ao Araxá. Não cabe retomar uma das mais antigas controvérsias da geologia nacional sobre o Grupo Araxá. É necessário lembrar, entretanto, que a única maneira de se identificar afinidades Brusque-Araxá seria um retorno às décadas de 50 e de 60 , quando essa última unidade abrangia uma vasta gama de seqüências supracrustais - incluindo diversos cinturões que viriam mais tarde a ser caracterizados com greenstone belts ou similares a greenstone belts. Evidentemente, não era essa a intenção de Soares (1988) ao propor a correlação. Acrescente-se, a título de reforço negativo, que a cartografia geológica na escala 1:100.000 em quatro folhas $(30 \times 30)$ do sudeste de Goiás, em execução no Programa Levantamentos Geológicos Básicos, tem permitido discriminar, sob os mais variados aspectos, associações terrígenas do tipo Araxá Canastra, de cinturões vulcanossedimentares pré-Araxá. É o caso específico da seqüência vulcanossedimentar Meia Ponte (Silvânia/Rio do Peixe), portadora de diversos elementos compatíveis com uma evolução similar à do Brusque - ao contrário das coberturas do Araxá.

A SUPOSTA CONEXÃO DAMARIANA $\mathrm{Na}$ primeira tentativa de correlacionar o evento Brasiliano/Pan-Africano por meio da conexão Damara-Ribeira, Porada (1979) interpretou as distintas seqüências brasileiras em ambiente de margem continental passiva, relativa à contrapartida damariana. Os dois segmentos foram interpretados em um modelo aulacogênico. Em trabalhos posteriores, o mesmo autor passou a admitir que a evolução do sistema rifte teria culminado com o desenvolvimento e consumo do assoalho oceânico no lado africano (Porada 1989). As demais tentativas de integração têm aceitado, com pequenas alterações, essas propostas aulacogênicas originais (e.g. Kaul 1979, Fragoso-César et al 1982, Bernasconi 1988, entre outros). Nenhum desses trabalhos abordou especificamente Santa Catarina, embora esse último autor (Bernasconi 1988), tenha interpretado a sedimentação Porongos, no Rio Grande do Sul, como representativa de depósitos plataformais do sistema Damara - Gariep e a contrapartida africana -, como depósitos eugeossinclinais da Formação Grootderm, a qual é atualmente considerada como um segmento ofiolítico com mais de $6.000 \mathrm{~m}$ de espessura (Porada 1989). Segundo essa interpretação, por se situar na margem passiva de um eogeossinclínio, o Complexo Brusque seria necessariamente correlacionado com os depósitos basais do sistema damariano (Grupo Nosib) e, mais especificamente, à base do rifte Gariep da Formação Stinkfontein (a litoestratigrafia do Cinturão Damara aqui adotada baseia-se na South African Committee for Stratigraphy SACS - Martin 1983).

Apesar dessas opiniões, o registro paleoambiental delineado no lado brasileiro desaconselha comparação direta com os $3.000 \mathrm{~m}$ de sedimentos flúvio-marinhos (deltaicos), associados ao vulcanismo félsico subaéreo da Formação Stinkfontein; e em relação ao fechamento (topo) do Grupo Nosib, constituído por mais de $6.000 \mathrm{~m}$ de depósitos vulcânicos félsicos e intermediários, incluindo ignimbritos (Formação Askevold/Naauwpoort) ou os carbonates das Formações Khan/Rossing em ambiente marinho plataformal - tampouco existe possibilidade de correlação.

Mesmo sem a pretensão de sugerir comparações baseadas apenas na literatura, seria possível considerar, pelo novo quadro aqui delineado, algumas similaridades entre a sedimenta- 
ção do estágio rifte do Grupo Nosib e da Formação Stinkfontein com a base Grupo Itajaí. Essa comparação torna-se mais atrativa se for levado em conta o desenvolvimento da Bacia Itajaí a partir de um (segundo) estágio de rifteamento néoproterozóico/eopaleozóico, representado por um pacote basal, ligado a um sistema deltaico com leques fluviais compostos por conglomerados polimíticos, arcóseos, arenitos líticos, arenitos vulcanogênicos e intercalações vulcanoclásticas (red beds) (Silva \& Dias 1981). As associações vulcanossedimentares do tipo Campo Alegre (SC), Bom Jardim (RS) e Guaratubinha (PR) - homólogos do Grupo Itajaí - poderiam ter correspondência com a Formação Askevold/Naauwpoort do Grupo Nosib. Os pacotes de turbiditos identificados no topo do Grupo Itajaí (Silva \& Dias 1981, Popp \& Silva 1985), bem como seus equivalentes no Rio Grande do Sul (Grupo Bom Jardim) e Paraná (Guaratubinha), - teriam correspondência nos Grupos Otavi e Swakop nos ramos damarianos central e setentrional. Falta, entretanto, um programa de integração geológica sistemática em ambas as margens continentais, indispensável para qualquer comparação mais consistente. Do lado brasileiro, existem dados isotópicos $\mathrm{Rb} / \mathrm{Sr}$ com resultados na ordem de $540 \mathrm{Ma}$ (Kaul 1982, Basei 1985, Basei \& Teixeira 1987), referentes à seqüência vulcanossedimentar e a granitos alcalinos associados no Grupo Itajaí. No lado africano, o magmatismo alcalino bimodal da Formação Naauwpoort foi datado em 840 Ma (Kroner 1982), enquanto no intervalo de $400 \mathrm{Ma}$ a $580 \mathrm{Ma}$, os registros referem-se a granitos pós-riftes (Martin 1983). Um lapso temporal expressivo deve ser admitido entre o inicio do estágio rifte em ambos os blocos, pecularidade que torna qualquer tentativa de correlação ainda mais precária. Além disso, o extensivo plutonismo cálcio-alcalino caracterizado como do tipo "I" - caledoniano por Basei (1985) e por ele relacionado a um evento colisional do tipo "A" na região, necessita ser melhor compreendido. As idades entre 620 Ma e 640 Ma que foram obtidas nos granitóides intrusivos do Cinturão Brusque (Granitos Valsungana e Guabiruba) e da Suíte Pedras Grandes, devido às suas características químicas e isotópicas crustais, favoreceriam uma evolução a partir da fase de rifteamento do Grupo Itajaí e não sintectonicamente ao principal evento deformacional registrado no Brusque, conforme sugerido no trabalho supramencionado.

Outras dificuldades para a correlação Itajaí/Damara referem-se ao distinto grau de metamorfismo e à distinta história metamórfico-deformacional. Do lado brasileiro, as condições metamórficas do Grupo Itajaí foram incipientes, possivelmente anquimetamórficas (Silva \& Dias 1981, Macedo et al 1984). No lado africano, o principal evento metamórfico atingiu a fácies anfibolito e teve uma evolução polifásica, sintectônica a uma fase tangencial não registrada no Grupo Itajaí, o qual é vinculado à tectônica transcorrente pós tangencial $(\mathrm{Dn}+2 / \mathrm{Dn}+3)$. Vale assinalar que o Damara distingue-se dos demais cinturões geossinclinais do sistema Pan-Africano, nos quais o metamorfismo seria igualmente incipiente (Martin 1983).
Em tentativas mais recentes de correlação, Porada (1989) relata que a identificação de sedimentos da fase rifte damariana, interdigitados em seqüências vulcanossedimentares até então consideradas como embasamento do rifte (Seqüência Sinclair, com idade de até $1.400 \mathrm{Ma}$ ), levantou uma nova discussão sobre critérios de discriminação entre os eventos tectono-termais Pan-Africano (Brasiliano) e Kibariano (Uruaçuano). De maneira análoga, a descoberta das associações vulcanossedimentares do lado brasileiro levaram ao questionamento das características plataformais e monocíclicas até então consideradas como diagnosticas da sedimentação brasiliana no sul do País. Como conseqüência, a evolução proterozóica em Santa Catarina pode ser entendida a partir de um evento multifásico de rifteamento, iniciado ao menos no Mesoproterozóico ( $>1.400 \mathrm{Ma})$, muito provavelmente no Proterozóico Inferior ( $>1.800 \mathrm{Ma})$, em um evento de ruptura intercontinental.

CONCLUSÕES E RECOMENDAÇÕES A execução de cartografia básica no pré-cambriano de Santa Catarina permitiu, com base na integração sistemática, questionar os modelos de evolução crustal monocíclica preconizados para a Província Ribeira/Mantiqueira no sul do país. Por meio de cronologia relativa de campo, foi possível antecipar em quase uma década, resultados radiométricos obtidos apenas recentemente, que enfatizam a importância do Proterozóico Inferior/Médio na evolução das denominadas Faixas Dobradas Proterozóicas. Dessa forma, nunca é demais chamar a atenção para a necessidade do emprego sistemático da cartografia geológica básica para a formulação de qualquer modelo consistente de evolução crustal, seja em pequenos ou em grandes tratos do Pré-Cambriano.

É recomendável, para futuros trabalhos, que sejam aprofundadas discussões a fim de proporcionar condições mais favoráveis à integração das distintas seqüências vulcanossedimentares da região centro-sul do País. Dessa maneira, poderão ser evitadas vinculações indesejáveis entre cinturões do tipo Brusque com o Cinturão Damara (stricto sensu), com o Grupo Açungui, o Grupo La Tinta, a Formação Maricá e, sobretudo, com o Bambuí.

Agradecimentos $\mathrm{O}$ autor deseja expressar agradecimentos ao Departamento de Ciências Geológicas (CPRM RJ), pelo apoio dado à livre circulação e veiculação de idéias pouco ortodoxas no Programa Levantamentos Geológicos Básicos. Ao colega Marco Aurélio Schneiders da Silva (CPRM - Porto Alegre), pela colaboração em diversos trabalhos executados na área e pela constante troca de opiniões sobre a geologia de Santa Catarina. Ao geólogo Reginaldo Alves dos Santos (CPRM - Salvador), pela elaboração das ilustrações esquemáticas que deram ao presente trabalho um qualificação especial. E, finalmente, aos geólogos Carlos Alfredo Bortoluzzi e João Awdiejz, do $11^{\circ}$ Distrito do DNPM em Florianópolis, pelo suporte institucional e incentivo em diversos trabalhos.

\section{REFERÊNCIAS BIBLIOGRÁFICAS}

ALMEIDA, F.F.M. 1967. Origem e evolução da Plataforma Brasileira. Rio de Janeiro, DNPM/DOM. 36 p. (Bol. 241)

ALMEIDA, F.F.M.; HASUI, Y.; NEVES, B.B.B. 1976. The Upper Precambrian of South America. Bol IG-USR, 7:45-80.

BASEI, M.A.S. 1985. O Cinturão Dom Feliciano em Santa Catarina. São Paulo. 196 p. (Tese de Doutoramento, IG/USP). (Inédito).

BASEI, M.A.S. \& TEIXEIRA, W. 1987. Geocronologia dos terrenos précambrianos a eopaleozóicos de Santa Catarina. In: SILVA, L.C. \& BORTOLUZZI, C.A. eds. Textos básicos de geologia e recursos minerais de Santa Catarina. Florianópolis, DNPM/SCTME. p. 91-129. (v. 1).

BEARDSMORE, T.T.; NEWBERRY, S.P.; LAINO, W.P. 1988. The Maronan Supergroup: an infered early volcanossedimentary rift sequence in the Mount Isa inlier, and its implication for ensialic rifting in the Middle
Proterozoic of Nothwest Queenland. In: WYBORN, L.A.I. \& ETHERIDOE, M.A. eds. The Early to Middle Proterozoic of Australia. Free. Research, 40/41:487-507. (Special Issue).

BERGMAN, M. 1988. Caracterização estratigráfica e estrutural da Seqüencia vulcano-sedimentar do Grupo São Roque na região de Pirapora do Bom Jesus, Estado de São Paulo. São Paulo. 165 p. (Dissertação de Mestrado, IG/USP). (Inédito).

BERNASCONI, A. 1988. Geological comparition of Precambrian and Early Paleozoic terranes between the southern west coast of Africa and the southeast of South America. Precambrian Research, 23:9-31.

BOUMA, A.H. 1962. Sedimentology of some flysh deposits. Amsterdam, Elsevier. $168 \mathrm{p}$.

CHAPPELL, B.I.W. \& WHITE, A.J.R. 1974. Two contrasting granite types. Pacific Geology, 8:173-174. 
CLEMENS, J.D.; HOLLOWWAY, J.R.; WHITE, A.J.R. 1986. Origin of A-type granite experimental constraints. Am. Mineral, 71:317-324.

DUNLOP, J.S.R. \& BUICK, R. 1981. Archean epiclastic sediments derived from mafic volcanics, North Pole, Pilhara Block, Western Australia. Geol Soc. Aust., 7:225-234. (Espec. PubL).

ETHIER, V.G. \& CAMPBELL, F.A. 1977. Tourmaline concentrations in Proterozoic sediments of the southern cordillera of Canada and their economic significance. Can. J. Earth. Sci, 14:2348-2363.

FISCHER, R.V. 1961. Proposed classification of volcanoclastic sediments and rocks. Geol. Soc. Am. Bull., 72:1409-1414.

FRAGOSO-CÉSAR, A.R.S. 1980. O Cráton do Rio de La Plata e o Cinturão Dom Feliciano no Escudo Uruguaio-Sul-Riograndense. In: CONOR. BRAS. GEOL., 31. Camboriú, 1980. Anais... Camboriú, SBO. v. 1, p. $1-12$.

FRAGOSO-CÉSAR, A.R.S.; WERNICK, E.; SOLIANI, E. 1982. Associacões petrotectônicas do Cinturão Dom Feliciano (SE da Plataforma Sul-Americana). In: CONOR. BRAS. GEOL, 32. SALVADOR. Anais. Salvador, SBG. v. 1, p. 1-12

GÉLINAS, L. \& BROOKS, C. 1974. Archean quench-texture tholeiites. Can. J. Earth. Sci., 11:324-240.

GÉLINAS, L.; BROOKS, C.; TRZCIENSKI, W.E. 1976. Archean variolites-quenched immiscible liquids. Can. J. Earth. Sci., 13:210-230.

GROSS, C.A. 1965. The geology of iron deposits in Canada: 1. General geology and evaluation of iron deposits. Econ. Geol Rep., (22):181 p.

GROVES, D.I. \& BATT, W.D. 1984. Spatial and temporal variations of Archean metallogenic in terms of granitoid-greenstone terrain with particular emphasis on the Western Australian Shield. In: KRONNER, A. HANSON, G.N. \& GOODWIN, A.M. eds. Archean Geochemistry. The Origin and Evolution of the Archean Continental Crust. Berlin, Springer-Verlag. p. 73-98.

GUPTA, A. BASU, A. SCHOSH, P K. 1982. Ultramafic Volcanoclastic of the Precambrian Dalma Volcanoclastic Belt, Singhbun, Eastern India. Geol Magazine, 119:505-510.

HASUI, Y.; CARNEIRO, C.D.R.; COIMBRA, A.M. 1975. The Ribeira Folded Belt. Rev. Bras. Geoc., 5(4):257-266.

ISSLER, R.S. 1982. Evento geodinâmico brasiliano-Fechamento de oceano e colisão continental dos Crátons Rio de La Plata e Dom Feliciano: granitos a duas micas e ofiolitos. In: CONOR. BRAS. GEOL., 32 Salvador, 1982. Anais... Salvador, SBG. v. 3, p. 24-36.

ISSLER, R.S. 1983. Evolução crustal da faixa arco-fossa Tijucas faixa mag mática Pedras Grandes: Cráton Dom Feliciano, In: SIMP. SUL-BRAS. GEOL., 1. Porto Alegre, 1983. Atas... Porto Alegre, SBG/NRS/NSC. p. 19-36.

ISSLER, R.S. \& FREIRE, F.A. 1985. A diversidade dos granitóides da região sul do Brasil. In: SIMP. SUL-BRAS. GEOL., 2. Florianópolis, 1985. Atas... Florianópolis, SBG/NRS/NSC/NPR. p. 89-101.

JULIANI, C.; BELJAVSKIS, P.; SCHORSCHER, H.D. 1986. Petrogênese do vulcanismo e aspectos metalogenéticos associados: Grupo Serra de Itaberaba na região de São Roque - SP. In: CONGR. BRAS. GEOL. 34. Goiânia, 1986. Anais... Goiânia, SBG. v. 2, p. 730-747.

KAUL, P.T.F. 1979. Precambriano e Eopaleozóico do nordeste de Santa Catarina e leste do Paraná: reavaliação de dados e correlação com a África. In: SIMP. REG. GEOL. Rio Claro, 1979. Atas... São Paulo, SBG/NSP. v. 1, p. 1-15.

KAUL, P.T.F.; COUTINHO, J.B.L.; ISSLER, R.S. 1982. O episódio Campo Alegre. In: CONGR. BRÁS. GEOL., 32. Salvador, 1982. Anais... Salvador, SBG. v. 1, p. 47-54.

KRONER, A. 1982. Rb-Sr geocronology and tectonic evolution of the PanAfrican Daman Belt of Namibia Southwest Africa. Am. J. Sci., 288:1471-1507.

LADEIRA, G.A. 1981. Primeiras lavas com almofada (pillow) encontradas no Super Grupo Rio das Velhas de idade arqueana no Quadrilátero Ferrifero e no Distrito de Pitangui, MG. Ciências da Terra, 1:12-14.

LIMA, R.E. \& LOPES, O.F. 1985. Evolução geológica da Formação Rio das Cobras no leste do Estado do Paraná. In: SIMP. SUL-BRAS. GEOL. 3. Florianópolis, 1985. Anais... Florianópolis, SBG/NRS/NSC/NPR. v. 1 , p. 53-59.
MACEDO, M.H.F.; BASEI, M.A.S.; BONHOMME, M.P.; KAWASffITA, K. 1984. Dados geocronológicos referentes às rochas metassedünentares do Grupo Itajaí (SC). Rev. Bras. Geoc., 14(1):20-34.

MANTOVANI, M.S.M.; HAWKESWORTH, C.J.; BASEI, M.A.S. 1987. Nd and $\mathrm{Pb}$ isotope studies bearing on the crustal evolution of southeastern Brasil. Rev. Bras. Geoc., 17(3):263-268.

MARTIN, H. 1983. Overview of the geossinclinal, structural and metamorphic development of the intracontinental branch of The Damara Orogen. In: MARTIN, H. \& EDER, F.W. eds. Intracontinental fold belts. Berlin, Springer-Verlag. p. 473-502.

MIYASHIRO, A. 1973. Metamorfism andMetamorphic Belts. London, Allen \& Unwin. 492p.

PINHEIRO, S.O. 1980. Petrografia da seqüência de rochas ígneas metamorfisadas de Pihum-hi. In: CONGR. BRÁS. GEOL., 31. Camboriú, 1980 Anais... Camboriú, SBG. v. 4, p. 2206-2214.

POPP, J.H. \& SILVA, L.C. 1985. Estratigrafia das bacias do Paraná e Itajaí, Perfil Lages-Blumenau. In: SIMP. SUL-BRAS. GEOL., 2. Florianópolis, 1985. Resumos e roteiros das excursões... Florianópolis, SBG/NRS/NSC/NPR. p. 49-74.

PORADA, H. 1979. The Damara-Ribeira Orogen of Pan-African-Brasilian Cycle in Namibia (Southwest Africa) and Brazil, interpreted in terms of continental collision. Tectonophysics, 57:237-268.

PORADA, H. 1989. Pan-African rifting and orogenesis in Southern to equatorial Africa and Eastern Brazil. Precambrian Research, 44:103-136.

SILVA, L.C. 1983a. O Complexo Metamórfico Brusque e a Seqüência Vulcano-Sedimentar Rio Itajaí-Mirim (SC): uma revisão. In: SIMP. SUL. BRAS. GEOL., 1. Porto Alegre, 1983. Atas... Porto Alegre, SBG/NRS/NSC/NPR. p. 253-265.

SILVA, L.C. 1983b. Basalto variolítico com matriz ultramáfica quench. Primeiras evidências de derrames komatiíticos (?) na Seqüência Vulcanosedimentar Rio Itajaí-Mirim (SC). In: SIMP. SUL-BRAS. GEOL., 1. Atas... Porto Alegre, SBG/NRS/NSC. p. 266-272.

SILVA, L.C. \& DIAS, A.A. 1981. Projeto Timbó-Barra Velha, Brasil Porto Alegre, Conv. DNPM/CPRM. 282 p. (Rel. Inéd.)

SILVA, L.C.; OLIVEIRA, J.M.P.; AUMOND, J.J.; LOPES, R.M.M.; EIPPER J. FERRO, G. 1985. Caracterização petrográfica da Seqüência (meta) Vulcano-sedimentar Rio do Oliveira (Cinturão Rio Itajaí-Mirim, SC). In: SIMP. SUL-BRAS. GEOL., 2. Florianópolis, 1985. Anais... Florianópolis, SBG/NRS/NSC/NPR. p. 11-23.

SILVA, M.G. 1984. A Seqüência vulcanossedimentar do médio Rio Itapicuru, Bahia: caracterização petrográfica, considerações petrogenéticas preliminares e zoneografia metamórfica. Geologia e Recursos Minerais do Estado da Bahia; Textos Básicos. Salvador, SME/CPM. v. 5, p. 6-42.

STEIN, D.P.; CAMPANHA, G.A.C.; FERNANDES, L.A. 1986. A Formação Perau na região de Pilar do Sul, SP. In: CONGR. BRAS. GEOL., 34 Goiânia, 1986. Anais... Goiânia. SBG. v. 4, p 919-930.

SOARES, P.C. 1988. Tectônica colisional em torno do Bloco Paraná. In: CONGR. LATINOAMER. GEOL., 7. Belém, 1988. Anais... Belém, SBG. v. 1, p. 63-70.

TEIXEIRA, N.A. \& DANNI, J.C.M. 1979. Geologia da raiz de um greenstone belt na região de Fortaleza de Minas, Minas Gerais. Rev. Bras. Geoc., 9(1): $17-26$.

TEIXEIRA, N.A. \& AITA, L. 1986. Contexto geológico das ocorrências de pirofilita entre Pitangui-Mateus Leme, MG. In: CONOR. BRAS. GEOL., 34. Goiânia, 1986. Boletim Resumos e Breves Comunicações.. Goiânia, SBG. p. 97-98.

TRAININI, D.R.; DIAS, A.A.; KREBS, A.S.J.; SOUZA, E.C.; CAPELETTI, L; TONIOLO, J.A.; SILVA, L.C.; SILVA, M.A.S. 1978. Projeto Vidal Ramos-Biguaçu. Porto Alegre, Conv. DNPM/CPRM. v. 1, 303 p. (Rel. Inéd.).

VIAL, D.S. 1986. O Complexo Brusque. DOCEGEO. 22 p. (Rel. Inéd.)

MANUSCRITO A642

Recebido em 19 de fevereiro de 1990

Revisão do autor em 24 de agosto de 1990

Revisão aceita em 27 de agosto de 1990 